\title{
Not all positive: On the landscape of thanking items in Cypriot Greek
}

Spyros Armostis \& Marina Terkourafi

University of Cyprus \& Leiden University

\section{Introduction}

There is no doubt that the publication of Sifianou's (1992a) Politeness phenomena in England and Greece has been a defining moment for the field of (Greek) politeness research. In that trend-setting work, Sifianou not only provided one of the earliest applications of Brown and Levinson's (1987) framework, she also set the tone for many a discussion of politeness in Greek (and many other languages/cultures) to follow. A central claim of Sifianou's work is that Greek does not share what one might call the Anglo-American 'obsession' with imposition but rather places equal, if not more, emphasis on solidarity. This led her to propose insightful analyses of, among others, diminutives (Sifianou 1992b), silence (Sifianou 1997), and speech acts such as compliments (Sifianou 2001), as solidarity-building devices, and more generally, to place positive politeness center-stage in the study of politeness in Greek (Sifianou 2015). Greek is by and large considered to be a positive politeness culture and subsequent analyses (Makri-Tsilipakou 2001, Tzanne 2001, Pavlidou 1994, 2001) served to confirm this general trend.

One aspect that is frequently overlooked in these discussions, however, is the type of speech on which many of these analyses have been based: urban, standard speech, as it is heard, for instance, in the major cities of Greece, Athens and Thessaloniki. Once the geographical lens is shifted to somewhat less standard varieties, such as Cypriot Greek, some interesting findings emerge.

Cypriot Greek, spoken natively by just over half a million speakers in Cyprus and by several hundred thousand living in the UK, Australia, and the US, is currently probably the most vivid variety of Greek other than Standard Modern Greek (SMG). Variably lauded for preserving ancient elements lost in other Greek varieties and stigmatized as "degenerate" due to contact with other languages (Machairas $§ 158$ cited in Terkourafi 2007: 78), Cypriot Greek has long been in a diglossic relationship with SMG as the High variety (Terkourafi 2005a, 2007; Tsiplakou 2006; Arvaniti 2010, among others). However, the economic successes of the 1980's and 90's, which also served to enhance Greek Cypriots' linguistic confidence, as well as more recently, standardization and codification efforts, mean that it is now more accurate to speak of a post-diglossic continuum, with basilectal varieties being most removed from SMG and acrolectal ones enjoying a high degree of intelligibility with it (Tsiplakou et al. 2006). In this complex socio-linguistic landscape, English, the language of colonial rule until 1960, and subsequently, of returning Cypriot emigrants and of new immigrants largely from South Asia and China, has variously contributed to the different registers, according to the abilities and preferences of the speakers (Tsiplakou 2009).

In terms of politeness, Cypriot Greek appears to be situated even further toward the positive end of the positive-negative politeness spectrum than SMG itself. $2^{\text {nd }}$ singular (T) forms are used overwhelmingly more than $2^{\text {nd }}$ plural (V) ones (Terkourafi 2005b) and imperatives are freely exchanged among interlocutors of various social ranks (Terkourafi 2005c). Diminutives, however, represent an anomaly in this respect: contrary to their extensive use in SMG, their use in Cypriot Greek was found to be limited to informal contexts and 
among intimates (Terkourafi 1999). Morphologically, too, diminution seems to be a more restricted process, not making use of the processes of compounding and syntactic diminution (with the adverb 'liy $\boldsymbol{O}_{\mathrm{r}}$ ) so common in SMG. This raises questions about how best to interpret diminutives in SMG as well: if they are viewed as wholesale positive politeness devices, it is hard to explain why they are not recruited to this same function in Cypriot Greek. A more realistic view is probably to acknowledge that processes of urbanization in Greece have created novel needs for societal and ethnic identification and that, in this context, diminutives may have metonymically extended their function from that of positive politeness to indexing (in the sense of Eckert 2008) a certain kind of urbanite sophistication that makes them appropriate for use in a far wider range of contexts than simply those calling for positive politeness (Terkourafi 2009). In Cyprus, on the other hand, where these same needs have not arisen to the same extent or are indexed differently, diminutives retained their more traditional role as positive politeness markers, and, consequently, their more limited distribution to primarily intimate contexts.

Thanking items in Cypriot Greek represent another arena in which the interplay between the Standard variety, Cypriot Greek, and English can be observed in full swing. In an article contrasting the use of thank you, please and sorry borrowed into Cypriot Greek from English with the corresponding inherited Greek terms (e)fiveri'sto ('to thank'), six: o' $r \boldsymbol{o}_{\mathrm{r}}$ ('to forgive') or si'ynomi(n) ('pardon'), and pereka'lo ('to ask/request'), Terkourafi (2011) argued that the latter more frequently serve politeness functions and are used as genuine expressions of the corresponding feelings, while the former tend to perform a variety of discourse functions such as conversational closings, repair, etc. With respect to thanking, she proposed a scale starting with the inflected verb efferi'sto, followed by invariable effieri'sto, phonologically truncated fiveri'sto and finally ' $\theta e_{i} c^{h} \cdot \boldsymbol{u}$, the nativized rendition of English 'thank you' (Figure 1).

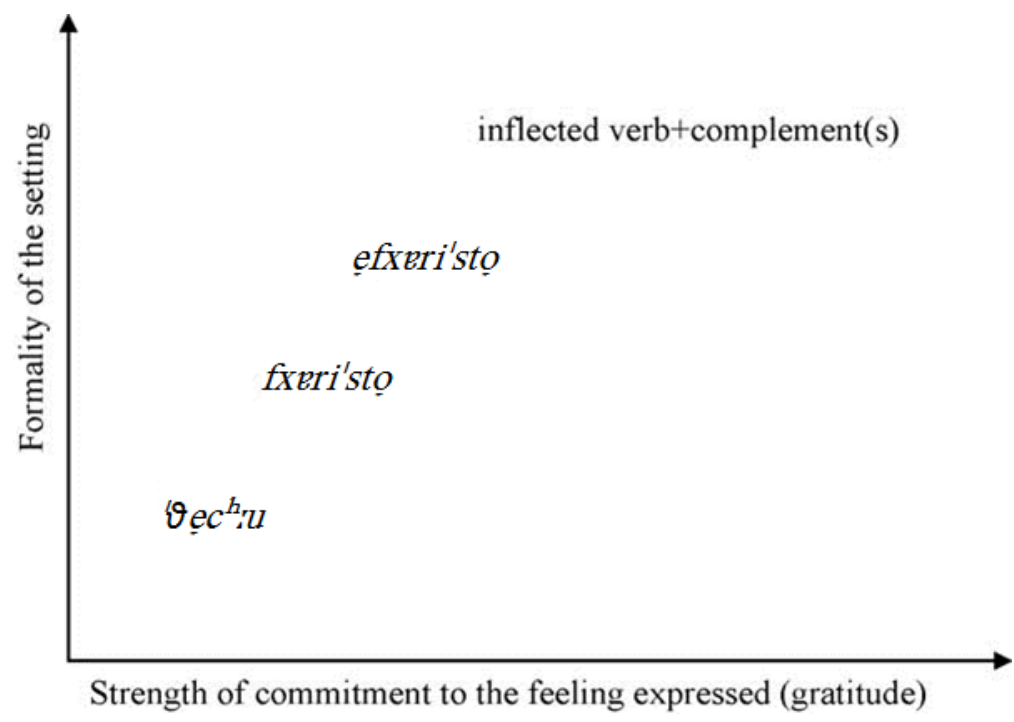

Figure 1: A ranking of inherited and borrowed expressions for thanking in Cypriot Greek (from Terkourafi 2011: 226).

In this scale, the sequence NP + inflected verb efferi' sto (+ CP) (see example (1)) is used in the most formal contexts and/or when the speaker's commitment to the illocutionary point expressed is greatest, while, conversely, ' $\theta e_{r} c^{h} \cdot \boldsymbol{u}$ is used mostly casually, in informal contexts, and often as a conversational closing (see example (2)). 
(1) ses effxeri'stume ' pere po'li pu 'isesten $e_{\tau}^{\prime} \partial o_{\tau}$ ce mes 'ipete ... (=Terkourafi 2011, ex. (13))

'We thank you very much for being here and telling us' ...

(2) ' $\theta e c^{\mathrm{h}}: \mathbf{u}($.$) 'pei (=Terkourafi 2011, ex. (18))$

'Thanks. Bye.'

Based on these findings, Terkourafi concluded that in Cypriot Greek, ' $\theta \underset{c}{ } c^{h} \cdot \boldsymbol{u}$ 'does little real thanking after all. Its main function is to fill an appropriate slot at the end of a transactional encounter, but this slot is mainly associated with leave-taking rather than gratitude in any real sense" (2011: 225).

Terkourafi's (2011) findings were based on a 60,000-word spoken corpus of spontaneous Cypriot Greek conversations in formal and informal settings collected in 1998. Those data represent native speakers' production and had not been originally gathered with a comparison of efferi'sto/ 'Aech: $\boldsymbol{u}$ in mind. While this guarantees the naturalness and spontaneity of the data, it can be limiting in other respects. Most notably, it circumscribes our ability to make claims about the interpretation and evaluation of these terms, which can only be inferred indirectly from the context and recipients' reactions (their "uptake"; Austin 1962), and to control for a number of contextual parameters and the phonetic realization of the terms. In this chapter, we revisit Terkourafi's earlier claims with the explicit aim of honing in on the contextual uses of ' $\theta e_{r} c^{h} \cdot \boldsymbol{u}$ (and, secondarily, efxeri'sto) and their interpretation and evaluation by native speakers of Cypriot Greek today. To this end, we report on two experiments, in which we manipulated the phonetic realization of these terms in different situational contexts and elicited specific judgments about their evaluation by native speakers.

Our investigation is in part inspired by the informal observation that nowadays - and

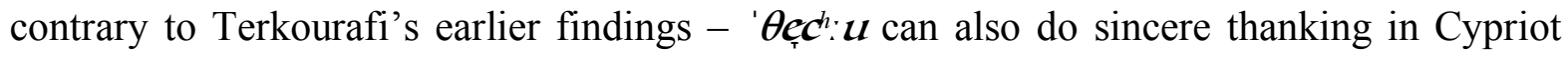
Greek. It is impossible to ascertain whether this represents a recent development or is a use of 'thank you' that was possible from the start, since the two datasets (from twenty years ago and from today) were compiled using different methodologies and with different research questions in mind. Nevertheless, we believe that the combined effect of social media and globalization, which has been associated with a more general trend toward the informalization

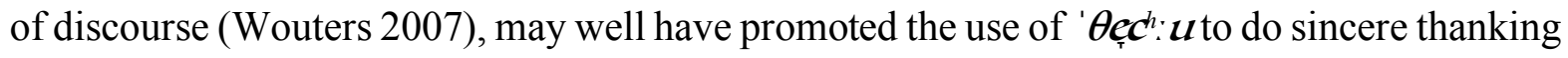
in Cypriot Greek.

Preliminary indications supporting the nativization of 'thank you' in Cypriot Greek and its expansion into thanking functions in at least some contexts come from online data. With regard to nativization, while $\theta \dot{\varepsilon} v \kappa l o v$ seems to be the preferred transliteration of 'thank you' in SMG online discourse (2,330 hits, only 197 out of Cyprus, i.e. less than 1 in 10), ${ }^{1}$ Cypriots' own preferred transliteration appears to be $\theta \dot{\kappa} \kappa l o v$ (291 occurrences, apparently all from Cyprus), a variant which, compared with $\theta \dot{v} v \kappa l o v$, reflects Cypriot phonological rules (most notably, nasal deletion before geminates; Newton 1972: 36). ${ }^{2}$ Interestingly, an even more informal version, $\varepsilon^{\prime} \kappa \kappa l o v$ with the initial fricative elided, occurs once on Twitter: ${ }^{3}$

\footnotetext{
${ }^{1}$ Figures correspond to Google searches from July 2015.

${ }^{2}$ English voiceless stops, such as /k/, are usually perceived as geminates by speakers of Cypriot Greek (cf. Newton, 1968: 24).

${ }^{3}$ Examples are cited using original punctuation and spelling.
} 


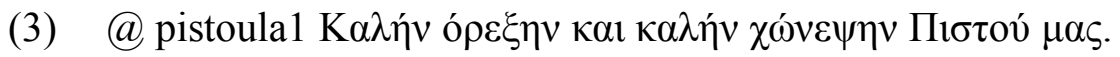

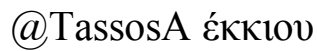

@ pistoula1 'Good appetite and good digestion, Pistou dear.'

@TassosA 'Thanks'

And while the SMG-preferred form $\theta \varepsilon$ vkııv is also used by Cypriots (see example (4)), it is less frequent and seems to acknowledge greater indebtedness than the nasal-less alternatives:

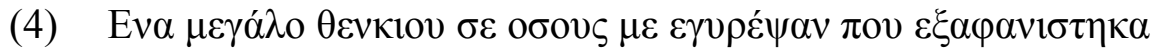

'A big thank you to those who looked for me while I was AWOL.'

The nativization of 'thank you' in Cypriot Greek is further supported by the co-occurrence of $\theta \dot{\varepsilon}(v) \kappa i o v$ with a variety of address terms, some (e.g., $\rho \varepsilon \alpha \mu \pi \alpha \dot{\lambda} \alpha \tau \varepsilon$, 'you dickhead' used affectionately, $\alpha \dot{\varepsilon} \rho \varphi \imath v$, 'bro' (dialectal)) more colloquial than others ( $\rho \varepsilon$, 'hey', $\varphi$ í $\varepsilon \mu o v$, 'my friend'), as well as code-switched ones (e.g., $\mu \alpha v$, 'man', $\mu \pi \imath \kappa \mu \pi \rho o \mu o v$ 'my big bro'). In fact, $\theta \dot{\varepsilon}(v) \kappa ı O v$ is generally frequent in code-switching environments (see example (5)), which have been claimed to correspond to a less formal register in Cypriot Greek (Fotiou 2015: 332 and the references therein): ${ }^{4}$

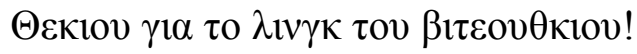

'Thanks for the link to the video-clip-DIM.!'5

With regard to its expansion into thanking environments and unlike in Terkourafi's earlier findings, the form $\theta \dot{\varepsilon}(v) \kappa i o v$ in Cypriot Greek online discourse appears to be fully syntactically productive and can occur with both clausal and NP complements, as in (6) and (7) below:

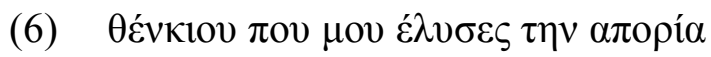

'Thanks for resolving my question.'

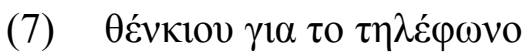

'Thanks for the call.'

Based on these indications from online discourse and on informal observation of natural speech, we hypothesize that ' $\theta e_{r} c^{h}: \boldsymbol{u}$ fulfills at least some thanking functions in contemporary Cypriot Greek and that such nativization of its functions will be reflected also in its form, specifically through two phonetic processes: $[\theta]$ deletion (associated with a more 'laid back' pronunciation) and [n] deletion (nasal deletion before geminates; Newton 1972: 36). Additionally, based on previous analyses of 'thank you'/'thanks' in English (Aijmer 1996, Archer et al. 2012, Wells 2006), we expect non-rising intonation to bias interpretation toward sincere thanking and, conversely, rising intonation to indicate a discourse marking function (henceforth DM). Because the interpretation of ' $(\theta) \mathcal{e}(n) \boldsymbol{c}^{h} \cdot \boldsymbol{u}$ as doing sincere thanking or as a $\mathrm{DM}$ is also likely to be modulated by context, we additionally expect social variables, namely the degree of familiarity between interlocutors, their gender, and the degree of imposition entailed by the performed act, to play a role in this case. To investigate the intersection of these

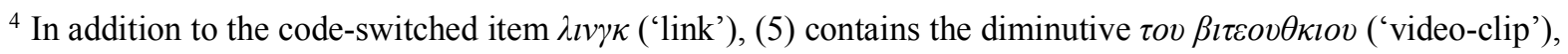
which is itself morphophonologically adapted to Cypriot Greek.

${ }^{5}$ Code-switched items are italicized in the English gloss; DIM.= diminutive.
} 
phonetic and social variables, we conducted two experiments. The first experiment aimed to identify under what phonetic and social conditions 'thank you' is most likely to be perceived as doing sincere thanking vs. as a DM. The second experiment focused on the various phonetic realizations of ' $(\theta) \mathcal{e}(n) \mathcal{C}^{h} \cdot \boldsymbol{u}$, which the first experiment identified as doing sincere thanking and investigated how native speakers of Cypriot Greek evaluate these in comparison with the inherited term for thanking, efferi'sto.

\section{First Experiment}

\subsection{Materials}

The goal of Experiment 1 was to identify the combination(s) of phonetic and social variables most conducive to interpretation of ' $(\theta) e(n) \boldsymbol{c}^{h}$ : $\boldsymbol{u}$ as sincere thanking or as a DM. Three phonetic dimensions of variation were independently manipulated: $[\theta]$ deletion vs. [ $\theta]$ retention; $[n]$ deletion vs. [n] retention; and rising vs. non-rising intonation. In addition, three social dimensions of variation were manipulated: talker gender (male vs. female); the degree of familiarity between interlocutors (familiar vs. unfamiliar); and the degree of imposition entailed in the context at hand (low vs. high). For each gender, we constructed four pairs of fictional contexts: two context pairs in which interlocutors were unfamiliar with each other (e.g., strangers on the street) and two context pairs in which interlocutors knew each other (e.g., colleagues at work). The first of the two unfamiliar contexts was a high-imposition one (e.g., thanking a passer-by for picking up the speaker's sunglasses that had accidentally dropped on the pavement) and the second a low-imposition one (e.g., thanking the cashier at the grocery store for offering a plastic bag), and similarly for the two familiar contexts. This process was repeated for both male and female interlocutors, resulting in a total of eight maleto-male and eight female-to-female contexts.

A challenge faced by researchers investigating the sociopragmatics of non-standard varieties such as Cypriot Greek stems from the fact that these varieties are not normally used in writing. While native speakers have recourse to a variety of ways to represent their speech in writing, the relevant conventions are at best informal and no official standardized conventions are available for use in experimental research (Armostis et al. 2014). Subjects' lack of exposure to written Cypriot Greek means that presenting the contexts to them in writing could have an adverse effect on the naturalness of their responses. More generally, as Peterson and Vaattovaara (2014: 258) have remarked, it can be problematic when forms that are more firmly entrenched in spoken or informal domains appear in a formal written format. To counteract this possibility, we opted for auditory rather than written presentation of the contexts to experimental subjects. Contexts were recorded and played back to subjects over headphones. Additionally, we used drawings to remind subjects of the contexts they had heard. This methodological move can counteract potential adverse effects from the written representation of non-standard speech more generally, provided drawings remain neutral as to the dependent variables under investigation. Figure 2 shows an example of a pair of contexts used in our study followed by the narrative description of the two contexts heard by subjects. 


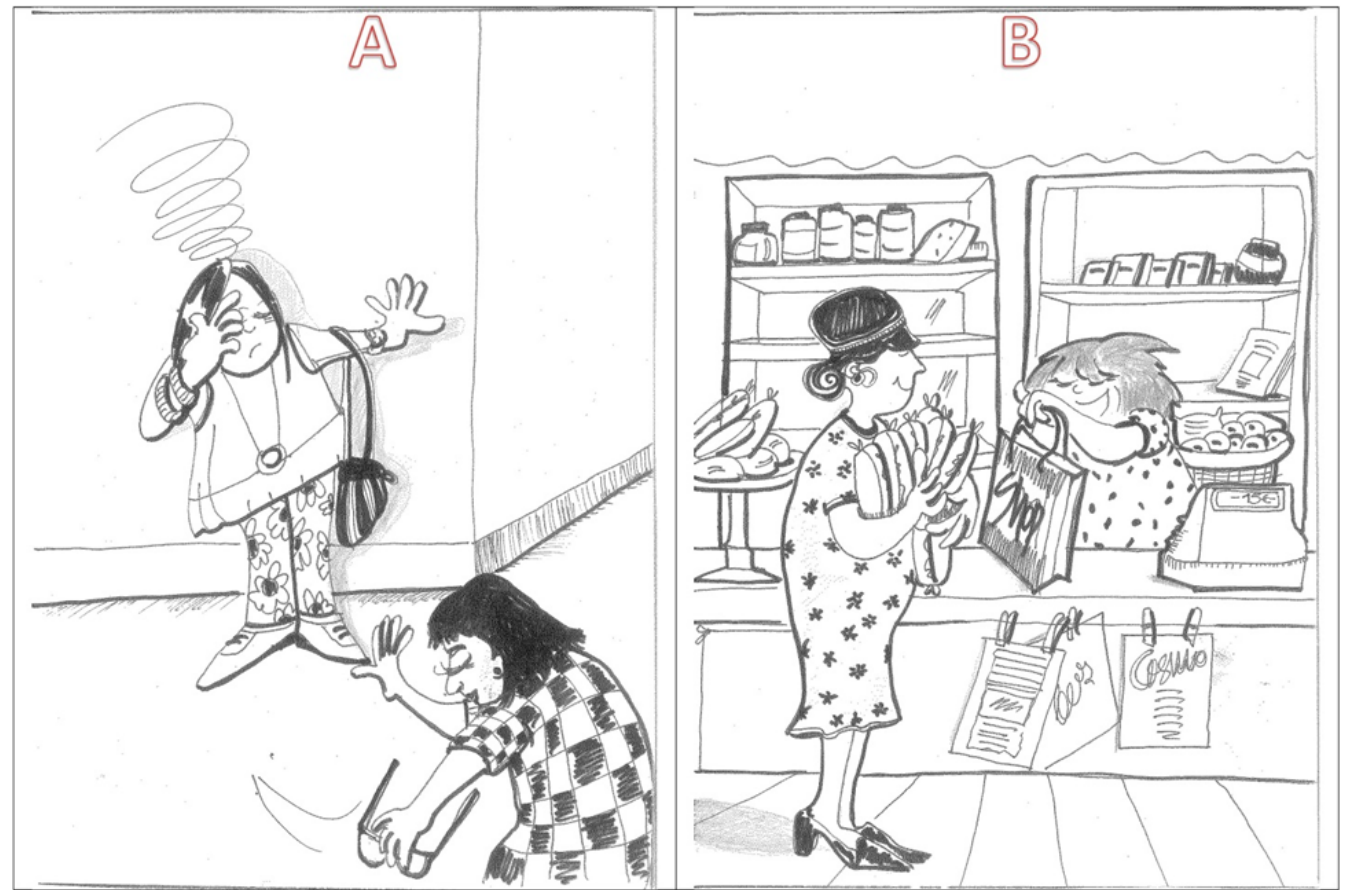

Figure 2: Example of drawings given to subjects representing two contexts with unfamiliar female talkers ( $\mathrm{A}=$ high-imposition context; $\mathrm{B}=$ low-imposition context).

Narrative description of context A (unfamiliar interlocutors in high imposition context): 'Elena is crossing the road, but she stumbles and her sunglasses fall off the top of her head. A woman passing by gives them to her and asks if she is alright. Elena replies:...'

Narrative description of context B (unfamiliar interlocutors in low imposition context):

'Elena went to the store to get sandwiches for her colleagues at work. As she was paying, the shop assistant asked her if she needed a plastic bag. Elena replies:...'

The audio-recorded narrative descriptions of the 16 contexts (eight male and eight female) were spoken by a male native speaker of Cypriot Greek. The responses following the narration at the end of the stories were spoken by two professional actors: a man for the male contexts and a woman for the female ones. To ensure the naturalness of their responses, the two actors were asked to role-play the part of the person saying ' $\theta$ ench $\boldsymbol{c}^{\mathrm{u}} \boldsymbol{u}$ in each of the eight contexts with the narrator as the interlocutor. Subsequently, they were asked to repeat the procedure first without the fricative $[\theta]$ and then without the nasal [n].

Next, the actors' recordings were phonetically manipulated using cross-splicing to produce the stimuli: with/without $[\theta] \times$ with/without $[\mathrm{n}] \times$ rising (e.g., ' $\left.\theta e n \nabla \boldsymbol{c}^{h} \cdot \boldsymbol{u}\right) /$ non-rising (e.g., ' $\theta \boldsymbol{\theta} \sqrt{\boldsymbol{V}} \boldsymbol{c}^{h} \cdot \boldsymbol{u}$ ) intonation, for a total of 8 stimuli for each gender. The stimuli with rising intonation were manipulated to ensure they all had exactly the same intonational pattern (which was the most natural-sounding rising-intonation pattern produced by each actor). The same procedure was followed for the non-rising-intonation stimuli. Four extra narratives were recorded (one high- and one low-imposition context for each gender) for the training portion of the experiment.

In sum, we created eight pairs of high- vs. low-imposition contexts (two contexts for each combination of level of familiarity $\times$ interlocutor gender), and eight phonetically manipulated stimuli corresponding to each of these pairs, which subjects heard twice (for a total of 16 trials 
for each pair of contexts). To avoid subject fatigue, materials were divided into eight counterbalanced blocks and the order of presentation was randomized.

\subsection{Subjects}

30 native speakers of Cypriot Greek (12M:18F) took part in Experiment 1. Their ages ranged between 19 and 46. All had received tertiary education.

\subsection{Procedure}

The experiment followed a matched-guise procedure and was run on a laptop using the Praat software (Boersma \& Weenink 2016). Subjects were given hard copies of five pairs of drawings (such as those shown in Figure 2) corresponding to the one training plus four experimental pairs of contexts. For each pair of contexts, they listened to the Cypriot Greek narrative descriptions of the high- and low-imposition contexts (with the order of presentation of the two types of contexts counter-balanced and the final turn, $(\theta) \mathcal{e}(n) \boldsymbol{c}^{h} \cdot \boldsymbol{u}$, omitted) and were instructed to refer to these as context A and context B. After listening to both contexts, they heard one of the ' $(\theta) \mathcal{e}(n) \boldsymbol{c}^{h}: \boldsymbol{u}$ stimuli and were asked to indicate which context, A or B, it matched best. Matching the stimulus with the high-imposition context was interpreted as attaching a sincere thanking function to it, while matching it with the low-imposition context was interpreted as indicating interpretation as a DM. This procedure was repeated 16 times, until all eight different stimuli had been heard twice in a randomized order. To further gauge subjects' level of certainty in their responses, we asked them to select between: (1) definitely A, (2) probably A, (3) maybe A, (4) maybe B, (5) probably B, (6) definitely B. Subjects were allowed to replay each stimulus once. After completing all 16 trials for a pair of contexts, they were instructed to pull out the next pair of drawings before listening to the next pair of contexts.

\subsection{Measurements}

To find out how often and in which contexts subjects perceived ' $(\theta) \mathcal{e}(n) \boldsymbol{c}^{h}: \boldsymbol{u}$ as a DM as opposed to sincere thanking, we measured the percentage of matching the stimulus with a lowvs. high-imposition context, respectively. For this measurement, the six options were collapsed to just two: 'A' and 'B'. Certainty, being an ordinal scale of measure ( 1 = 'maybe', $2=$ 'probably', 3 = 'definitely'), cannot be reported using mean values. The skewness of the certainty distribution is reported instead, with values ranging from -1 (greater certainty) to +1 (greater uncertainty). We will thus be referring to 'uncertainty,' which increases as skewness increases.

\subsection{Results}

For the statistical analysis, the rate at which experimental subjects matched the stimulus with a low-imposition context (i.e., the rate at which they interpreted it as a DM), was used as the dependent variable of a mixed-design ANOVA. The within-subjects (repeated measures) independent variables were: (1) Fricative Deletion (without vs. with [ $\theta]$ ); (2) Nasal Deletion (without vs. with [n]); (3) Intonation (non-rising vs. rising); (4) Familiarity (unfamiliar vs 
familiar interlocutors); and (5) Talker Gender (female vs. male). The between-subjects independent variable was Subject Gender (female vs. male). Since the dependent variable is expressed in a proportional scale (as a rate percent), it does not follow a normal distribution. The dependent variable was transformed using Studebaker's (1985) 'rationalized arcsine transform', which is especially designed for stabilizing the variance of proportional scales in order to be admitted in an ANOVA test. The transformed data did not always obtain a normal distribution; however, as ANOVA is robust to violations of normality assumptions (see Glass et al. 1972), the analysis was still conducted with the caveat that the results should be treated with caution, especially when the effect size was small.

The statistical analysis showed that the only independent variables with significant main effects were Intonation, $F(1,28)=12.028, p=.002$, partial $\eta^{2}=.300$, and Talker Gender, $F(1,28)=5.219, p=.030$, partial $\eta^{2}=.157$. The only significant simple interaction was Familiarity $\times$ Intonation, $F(1,28)=6.324, p=.018$, partial $\eta^{2}=.184$. As Figures 3 and 4 show, ${ }^{6}$ stimuli with rising intonation were perceived as a DM more frequently than stimuli with non-rising intonation. With rising intonation, the stimulus was perceived as a DM 67\% of the time ( $S E=19 \%$ ), while with non-rising intonation, it was perceived as sincere thanking $61 \%$ of the time $(S E=19 \%)$. Subjects were slightly more certain about their answers with rising $($ skew $=.027)$ than with non-rising intonation stimuli $(s k e w=.048)$. The presence or absence of $[\theta]$ and [n] (four left pairs of bars in Figure 4) had no effect on how the stimulus was perceived (percentages were always close to chance level, i.e. 50\%).

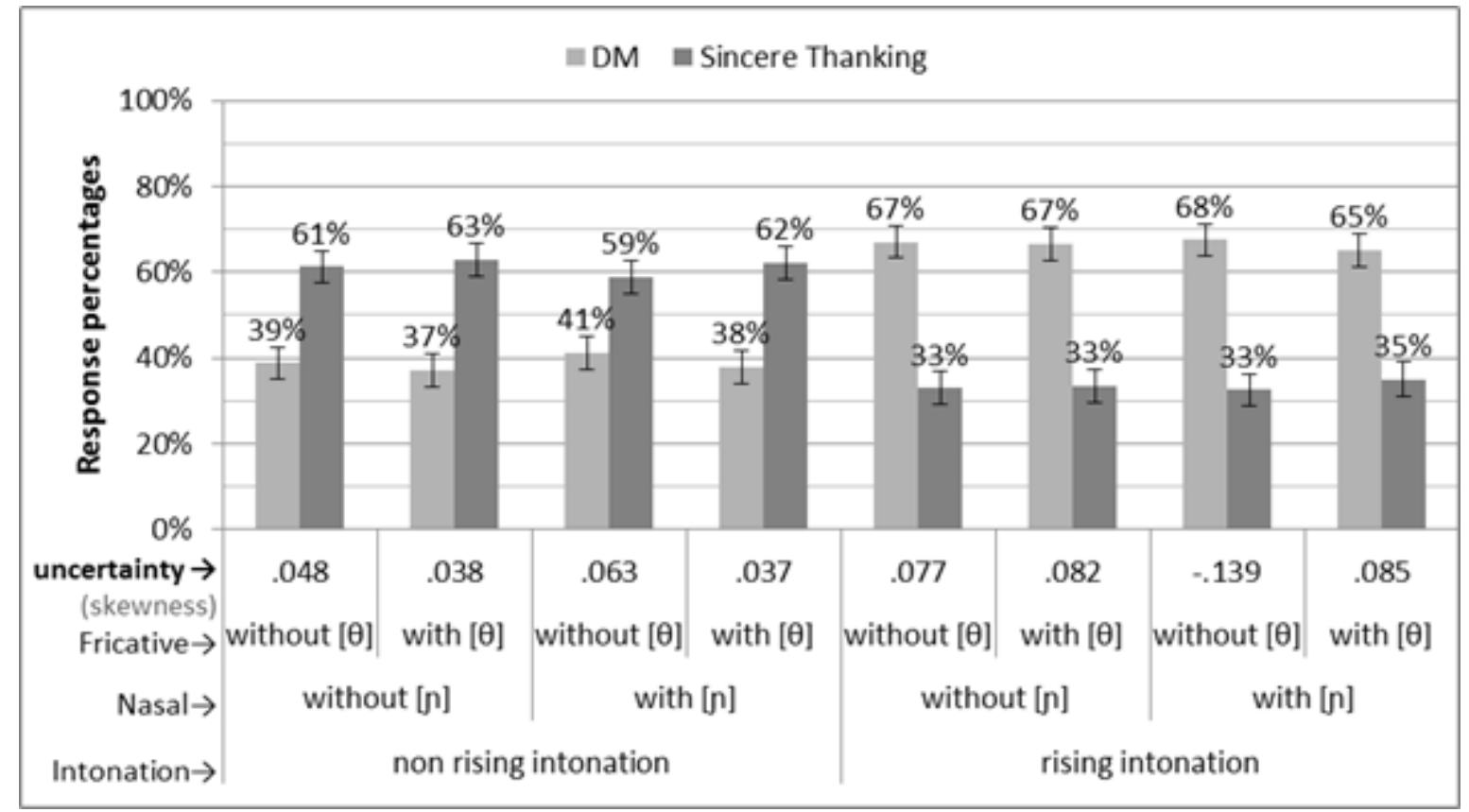

Figure 3: Percentages of DM vs sincere thanking responses as a function of all three phonetic variables combined.

\footnotetext{
${ }^{6}$ In these and the following Figures, error bars show $1 S E$ of the mean. The numbers below the horizontal axis indicate the uncertainty skewness.
} 


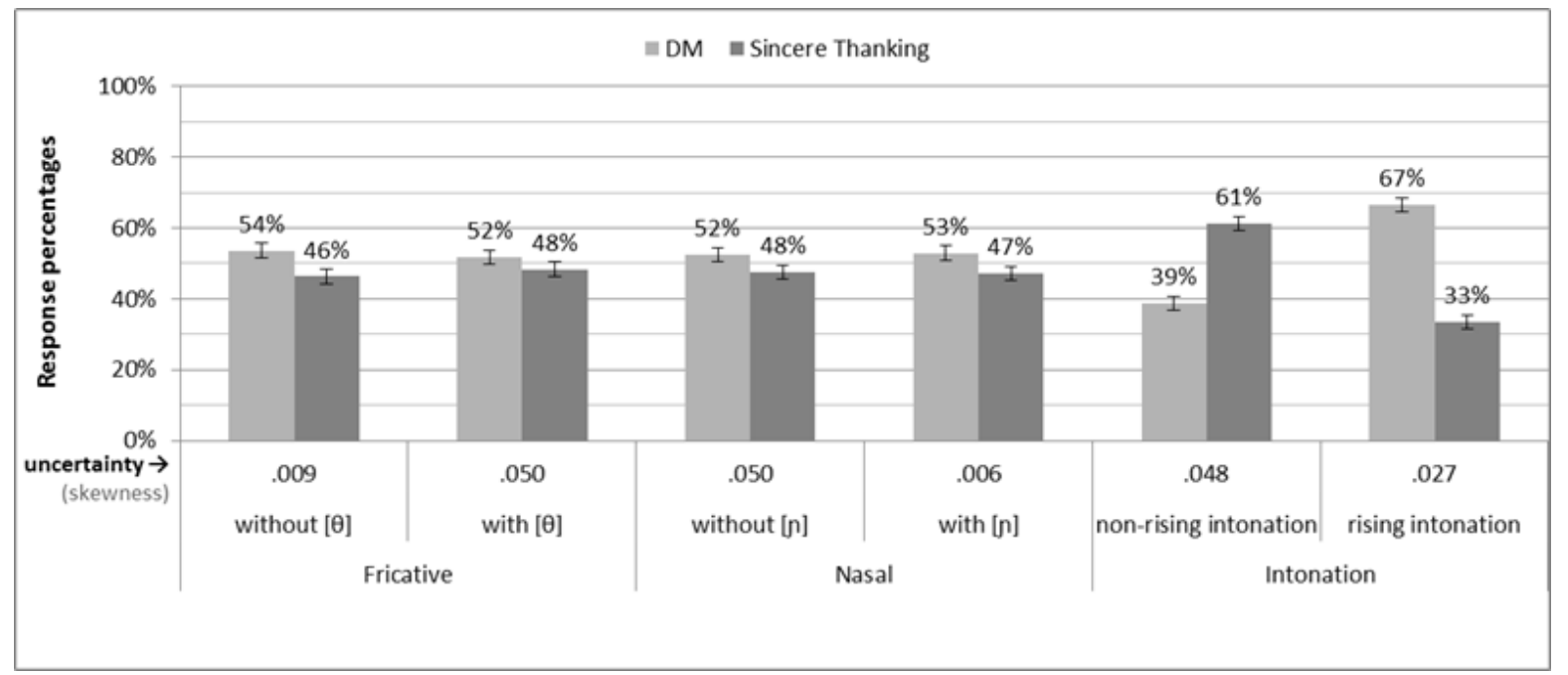

Figure 4: Percentages of DM vs sincere thanking responses as a function of (a) Fricative Deletion, (b) Nasal Deletion, and (c) Intonation presented separately.

Overall, the stimuli produced by males were perceived as a DM more frequently $(M=$ $56 \%, S E=2 \%)$ than those produced by females $(\mathrm{M}=49 \%, S E=2 \%)$, although subjects were more certain about their answers when listening to females $($ skew $=-.003)$ as opposed to males $($ skew $=.062)$. A simple main effect analysis performed separately for male and female talkers showed that the deletion of $[\theta]$ and $[\mathrm{n}]$ by female talkers did not influence the perception of the stimuli (see Figure 5). Rather, intonation was the crucial factor: 'thank you' with rising intonation spoken by females was perceived as a DM (64\%) and with non-rising intonation as sincere thanking $(65 \%), F(1,28)=7.055, p=.013$, partial $\eta^{2}=.201$. Similar results obtained for males: intonation was again the crucial factor: with stimuli with rising intonation spoken by males perceived as a DM (70\%) and with non-rising intonation as sincere thanking $(57 \%)$, $F(1,28)=10.138, p=.004$, partial $\eta^{2}=.226$.

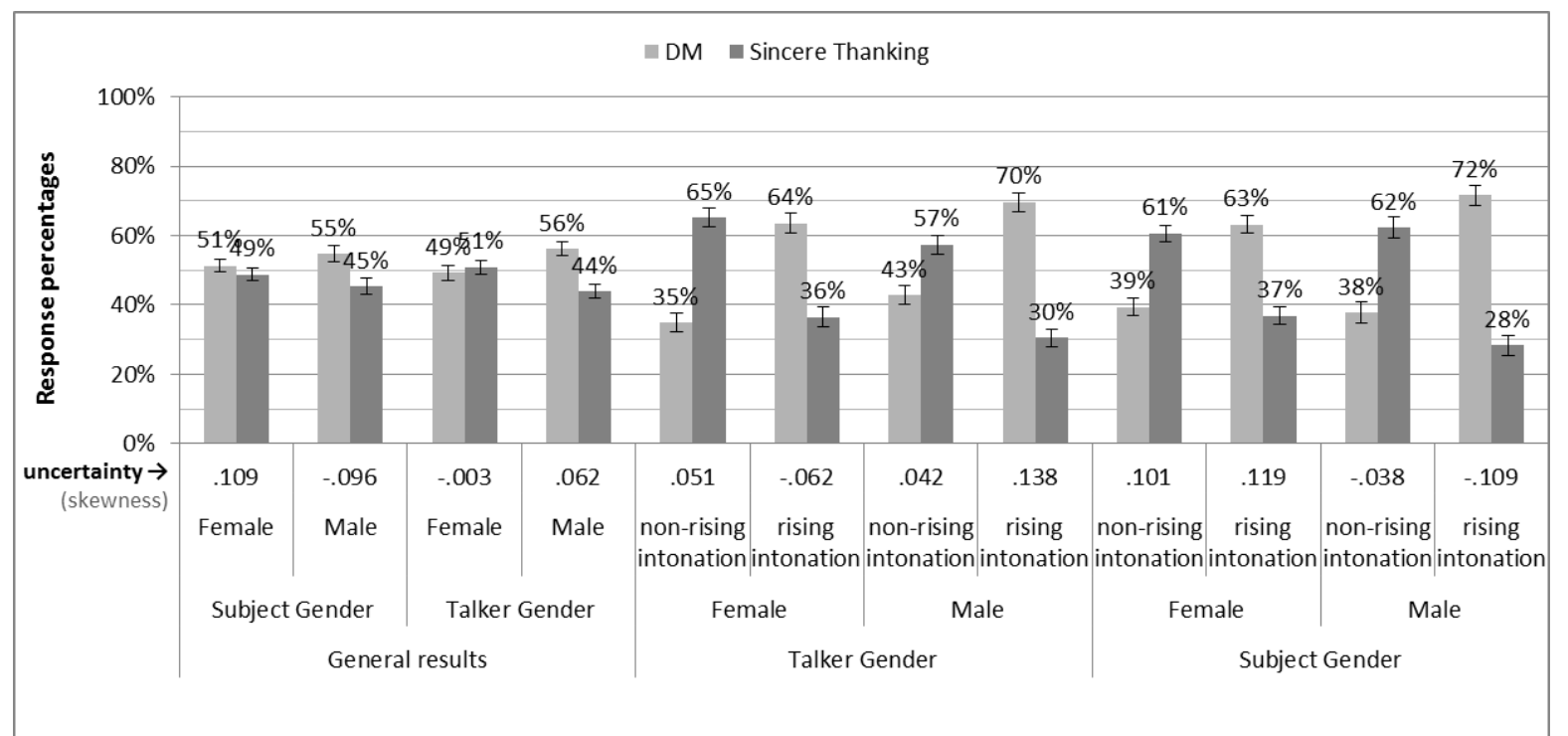

Figure 5: Percentages of DM vs sincere thanking responses as a function of Subject Gender, Talker Gender, and Intonation.

Intonation was the main factor that played a role for all combinations of the Subject Gender $\times$ Talker Gender interaction (see Figure 6). 


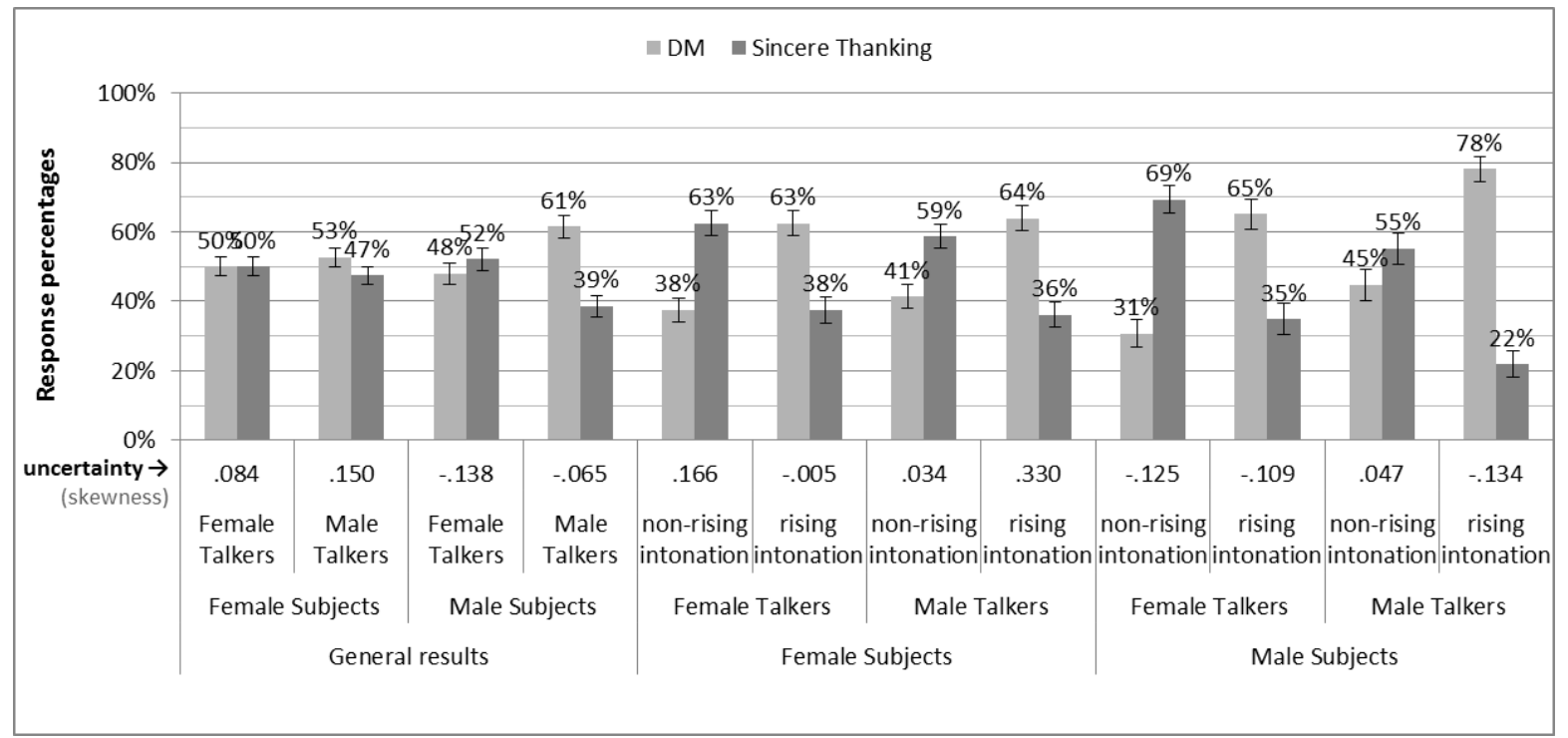

Figure 6: Percentages of DM vs sincere thanking responses as an interaction of Subject Gender, Talker Gender, and Intonation.

\subsection{Discussion}

The results of experiment 1 indicate that the decisive phonetic dimension for the interpretation of ' $(\theta) \mathcal{e}(n) \boldsymbol{c}^{h} \cdot \boldsymbol{u}$ by native Cypriot Greek speakers is intonation: stimuli with rising intonation were interpreted as a DM (matched with low-imposition contexts) 2 out of 3 times, while the opposite tendency (albeit slightly weaker) was noted for stimuli with non-rising intonation (they were matched with high-imposition contexts, i.e. interpreted as sincere thanking). Contrary to our hypothesis regarding the presence or absence of $[\theta]$ and $[n]$ indicating nativization of 'thank you' in terms of pronunciation (segmentals), these variables had no effect on how the stimulus was perceived. The importance accorded to intonation was confirmed by subject debriefing after the experiment (subjects could hear the differences between stimuli but commented that "there are only two variants"), and agrees with crosslinguistic findings about the interpretation of 'thank you'/'thanks' (Aijmer 1996, Archer et al. 2012, Wells 2006).

Zooming in on the role of intonation in our results, female talkers using rising intonation were perceived to be using ' $(\theta) \mathcal{e}(n) \nabla c^{h}: u$ as a DM 64\% of the time, a figure that rises to $70 \%$ for male talkers. Conversely, female talkers using ' $(\theta) \boldsymbol{e}(n) \boldsymbol{Y} \boldsymbol{c}^{h} \cdot \boldsymbol{u}$ with non-rising intonation were perceived to be doing sincere thanking $65 \%$ of the time, a figure that drops to $57 \%$ for male talkers. Although these tendencies do not reach statistical significance, they suggest that intonation played a more decisive role in determining interpretation in the case of female, as opposed to male, talkers. In other words, what a woman is doing with ' $(\theta) \boldsymbol{e}(n) \boldsymbol{c}^{h}: \boldsymbol{u}$ seems to depend crucially on intonation, while what a man is doing seems to be more closely tied to his choice of the lexical item itself: the interpretation of ' $(\theta) \mathcal{e}(n) \boldsymbol{c}^{h} \cdot \boldsymbol{u}$ as a DM when it is used by a man cannot as easily be undone by (non-rising) intonation. This suggests that ' $(\theta) e(n) \boldsymbol{c}^{h} \cdot \boldsymbol{u}$ doing sincere thanking in Cypriot Greek may be a feature of women's speech.

This suggestion gains some support from the gender of experimental subjects. Male subjects judged the various ' $(\theta) e(n) \boldsymbol{c}^{h}$ : $u$ realizations as a DM slightly more frequently and with higher certainty than female subjects did (see Figure 5). In other words, men, more so than 
women, are guided to the DM interpretation by the lexical item itself, irrespective of how it is phonetically realized.

A final piece of evidence supporting the association of ' $(\theta) \mathcal{e}(n) \boldsymbol{c}^{h} \cdot \boldsymbol{u}$ as sincere thanking with female speech in Cypriot Greek comes from the interaction of talker gender with subject gender. While for female subjects, intonation alone determined whether ' $(\theta) \mathcal{e}(n) \boldsymbol{c}^{h} \cdot \boldsymbol{u}$ was interpreted as a DM or not, male subjects thought female talkers were more likely to be using $'(\theta) \mathcal{e}(n) \boldsymbol{c}^{h}: \boldsymbol{u}$ to do sincere thanking than male talkers were. Conversely, when the talker was female, male subjects perceived stimuli with non-rising intonation as sincere thanking more frequently than when the talker was another male (see Figure 6). This indicates, again, that for male subjects the choice of the lexical item alone by male talkers is a strong indicator that they are using it as a DM, with intonation playing a secondary role.

An interesting hypothesis suggested by these results is that ' $(\theta) \mathcal{e}(n) \boldsymbol{c}^{h}: \boldsymbol{u}$ in women's speech in Cypriot Greek serves two functions, a DM and a thanking function, and this ambiguity is largely resolved through intonation, while in men's speech, ' $(\theta) \boldsymbol{e}(n) \boldsymbol{c}^{h}: \boldsymbol{u}$ serves a DM function, with intonation playing a secondary role. In light of the sociolinguistic finding that (especially young) women tend to be agents of language change (however that is interpreted; e.g., Labov 1994; Romaine 2000: 147-148), this raises the possibility that the expansion of ' $(\theta) \mathcal{e}(n) \boldsymbol{c}^{h} \cdot \boldsymbol{u}$ into sincere thanking in Cypriot Greek is an ongoing change led by (young) women. Several tendencies in our results point in this direction, making this a fruitful avenue for future research.

\section{Second Experiment}

Having found that ' $(\theta) \mathcal{e}(n) \mathcal{C}^{h} \cdot \boldsymbol{u}$ can (also) do sincere thanking in contemporary Cypriot Greek, and that this interpretation is primed by non-rising intonation and possibly also associated with women's speech, we set out to investigate its relation to other items available to do thanking in Cypriot Greek. In particular, we were interested in how ' $\theta e n c^{h} \cdot \boldsymbol{u}$ compares with inherited efferi'sto, which carried the burden of sincere thanking in Terkourafi's (2011) data. Additionally, we wanted to explore the interface of the borrowed and inherited thanking items with address terms (henceforth AT). Informal observation and some of Terkourafi's (2011) results (see also her example (49)) had already suggested that addition of an informal AT increases the likelihood of the perception of sincere thanking. As sincere thanking is the focus of our second experiment, investigating the impact of the presence/absence of a familiar AT can give us a more comprehensive picture of how that is achieved in Cypriot Greek. Thus, the research questions experiment 2 sought to address were the following:

1. How do speakers of Cypriot Greek evaluate the two variants of ' $\theta \boldsymbol{e n} \boldsymbol{c}^{h}$ : $\boldsymbol{u}$ (i.e. with rising and non-rising intonation) in high- and in low-imposition contexts?

2. How do they evaluate efferi'sto (with rising and non-rising intonation) in the same contexts?

3. What is the effect of adding a familiar AT, such as First Name + 'mu' (i.e. 'my FN'), on the evaluation of ' $\theta e n c^{h}: \boldsymbol{u}$ vs. eftureri'sto (with rising and non-rising intonation) in these contexts? 


\subsection{Design}

To answer these questions, we designed a language attitude experiment aimed to elicit native speakers' evaluations of ' $\theta$ ench:u and efueri'sto in a variety of contexts on fourteen dimensions: intelligent, unrefined, off-putting, ambitious, self-confident, backward, arrogant, friendly, sincere, distant, formal, polite, curt, and phony (for the original Greek terms used, see Appendix A). This list was adapted from previous language attitude studies (e.g., Salmon \& Gomez Menjivar 2014) going back to Woolard's landmark analysis of attitudes to Catalan and Castilian in Catalonia (1989). Additionally, we tried to counter-balance the number of positive (e.g., 'intelligent') and negative (e.g., 'off-putting') dimensions, to ensure that subjects considered each dimension separately and were not biased toward either direction by the greater (or lesser) number of positive or negative terms provided.

\subsection{Materials}

Contrary to experiment 1 , in experiment 2 only contexts with familiar interlocutors were used. This choice was dictated by the fact that, while a generic AT for use with unfamiliar male addressees is widely established in Cypriot Greek ('file mu, 'my friend'), no equivalent AT for use with unfamiliar female addressees is available. For our second experiment, therefore, we kept half of the contexts from experiment 1 (those with familiar interlocutors) and complemented them with an equal number of contexts created expressly for this experiment. In all, eight all-female and eight all-male contexts were used, four high-imposition and four low-imposition ones. The narrative descriptions of the newly created contexts were again spoken and audio-recorded by a male narrator, as described in section 2.1 above.

The stimuli subjects were asked to evaluate varied with regard to three factors: (a) the thanking item ( ' $\theta e n c^{h}: \boldsymbol{u}$ or efferi'sto); (b) intonation (rising or non-rising); and (c) presence or absence of an AT after the thanking item. The new stimuli were produced by the male actor of experiment 1 and a new female actor using role-playing, as described for experiment 1. However, this time the pitch of the recorded stimuli was not manipulated, as the stimuli differed in terms of syllables depending on whether they contained an AT and on the length of the name within the AT (e.g., me 'rie $m u$, 'my Maria', 'el: $i m u$, 'my Elli' etc.). Since the intonational patterns of the stimuli could not be exactly the same, the most similar sounding rising and non-rising patterns among stimuli from (at least) two repetitions of each stimulus produced by the actors were selected based on auditory similarity, also aided by visual inspection of the pitch contour in the Praat speech processing software. Examples of the intonation of the two patterns can be seen in Figures 7 and 8. Subsequently, the recording of each narrative description of the contexts was combined with all eight variants of the response $(2$ thanking items $\times 2$ intonation patterns $\times 2$ AT) yielding 64 female stimuli and 64 male stimuli. ${ }^{7}$ An additional context with female interlocutors was created for the training phase of the experiment. To avoid subject fatigue, these materials were divided into 20 counterbalanced blocks of 8 contexts each.

\footnotetext{
${ }^{7}$ Four male contexts with unfamiliar interlocutors in which the AT 'filẹ $m u$ is used were included in the design (yielding 32 additional stimuli). These are not analyzed in the current study.
} 


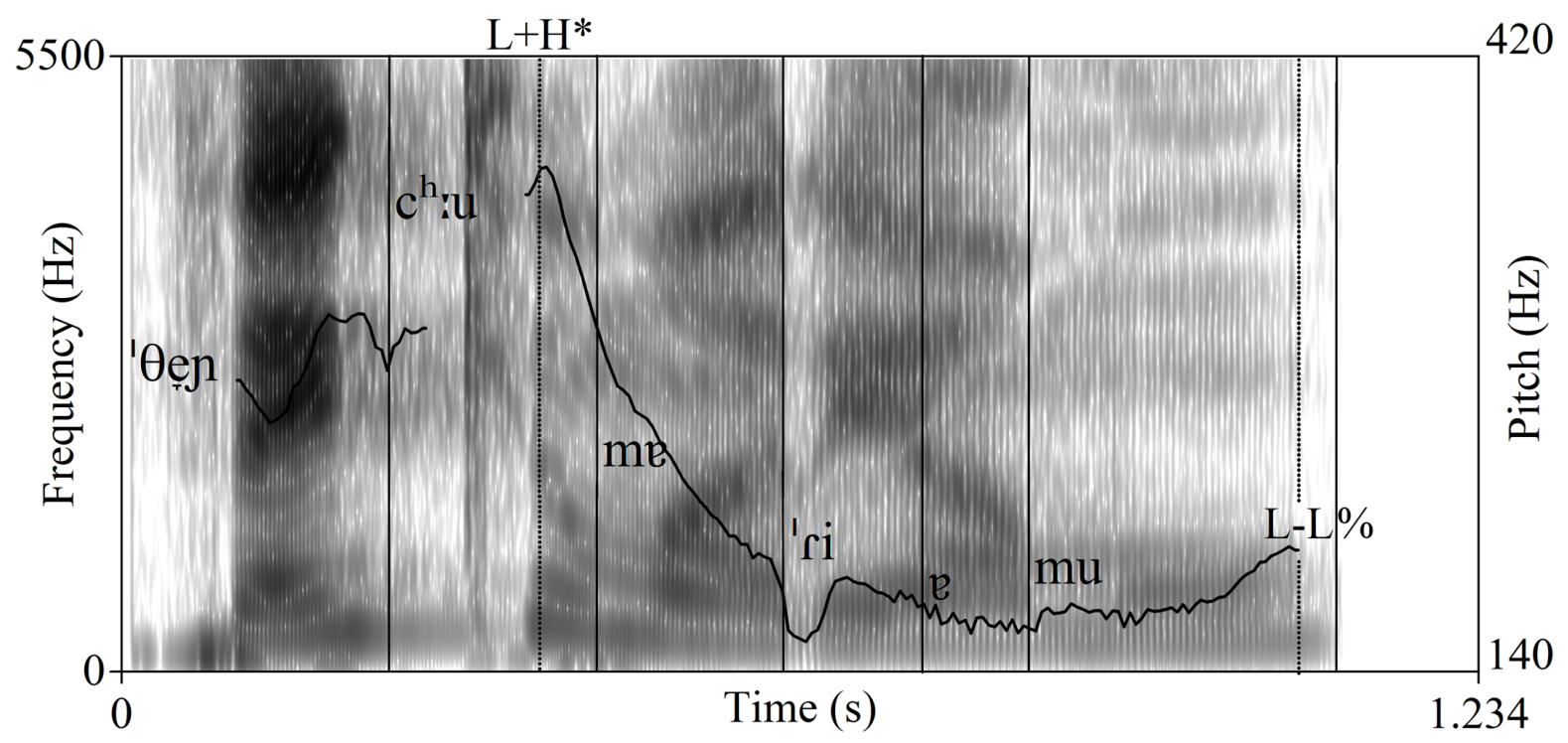

Figure 7: Annotated spectrogram and f0 curve of the phrase [' $\theta e \mathbf{e s c}^{\text {h' }} \mathbf{u} \mathbf{m e} \mathbf{e}^{\prime} \mathbf{r i e} \mathbf{m u}$ ] with non-rising final intonation.

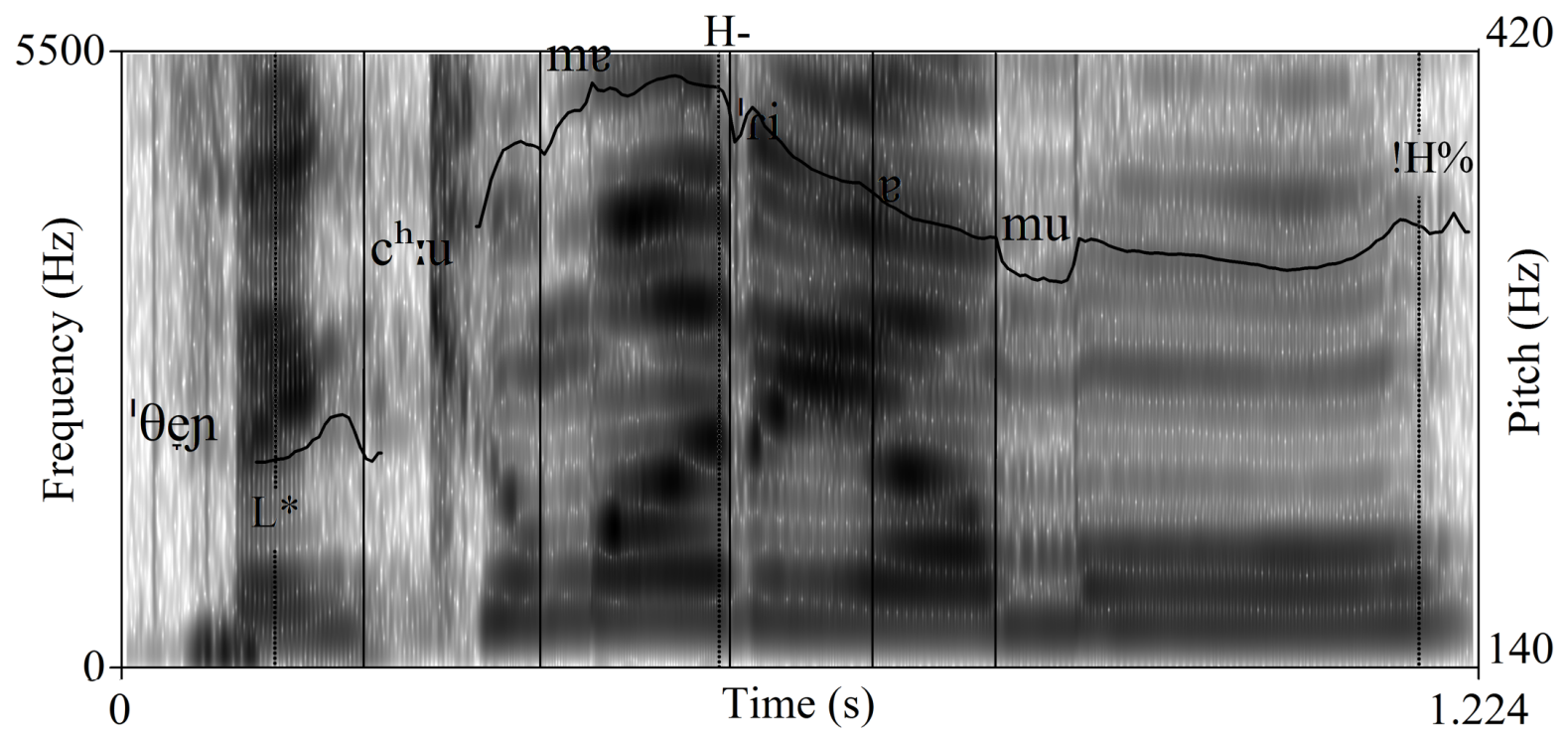

Figure 8: Annotated spectrogram and $\mathrm{f0}$ curve of the phrase [' $\theta e \mathrm{enc}^{\mathrm{h}}: \mathbf{u} \mathbf{m e}$ ' $r \mathbf{i} \mathbf{m u}$ ] with rising final intonation.

\subsection{Subjects}

37 native speakers of Cypriot Greek (18M:19F) took part in experiment 2. All had received tertiary education and their ages ranged between 20 and 40. None had taken part in experiment 1.

\subsection{Procedure}

The experiment was run on a laptop using the DMDX display software (Foster \& Foster 2003). At the beginning of the experiment, subjects were instructed to evaluate the talker based on his/her reply in the specific context. The subjects heard the stimuli (consisting of the descriptive narrative plus the thanking final turn) through headphones. After each stimulus, they were asked to rate the talker on a 6-point Likert scale ranging from 1 (=not at all) to 6 (=very much) for each of the fourteen dimensions listed in section 3.1. The order of 
presentation of the stimuli was randomized, as was the order of the fourteen dimensions presented after each stimulus.

\subsection{Measurements}

The main measurement taken was the agreement score (ranging from 1 to 6) for each of the fourteen dimensions: the higher the score, the more the subjects agreed that the specific dimension characterizes the reply of the talker in the context heard. Additionally, we measured reaction times; however, we do not report these in the present analysis.

\subsection{Results}

Since the dependent variable was measured at the ordinal level, we used non-parametric tests, in particular, the Durbin test (see Conover 1999: 388-395), as the most appropriate for experiments using a balanced incomplete block design, such as our experiment 2 . The test was run fourteen times, once for each dimension of evaluation, in order to find out whether the various combinations of conditions (imposition $\times$ thanking item $\times$ intonation $\times$ AT) had any effect on subjects' judgements for that dimension. Subsequently, pairwise comparisons of the various combinations of conditions were run within each of the fourteen tests. Below, we focus on the most important of these comparisons, reporting results at the $\alpha=.001$ level of significance.

For six of the fourteen dimensions investigated, the results of the Durbin test were not significant (and neither were subsequent pairwise comparisons at $\alpha=.001$ ). Those were: selfconfident $\left(T_{2}=1.262, p=.283\right)$, distant $\left(T_{2}=1.648, p=.144\right)$, sincere $\left(T_{2}=1.672, p=.137\right)$, ambitious $\left(T_{2}=3.286, p=.010\right)$, backward $\left(T_{2}=2.808, p=.023\right)$, and polite $\left(T_{2}=2.498, p=\right.$ $.028)$. Another two dimensions, intelligent and unrefined, yielded significant results at the $\alpha=$ .001 level in the Durbin test (intelligent: $T_{2}=20.080, p<.0005$; unrefined: $T_{2}=5.753, p<$ $.0005)$; however, when pairwise comparisons were subsequently conducted, their results were not significant at this level either. This means that there was not a particular combination of the linguistic variables manipulated (lexical items, intonation, presence/absence of AT) that subjects judged to be significantly more 'intelligent' or 'unrefined' when compared to another, and as such we do not comment on these further here. For the remaining six dimensions, results from the pairwise comparisons were significant at $\alpha=.001$. In addition, for most of these, the results of the Durbin test were also significant. Below, we focus on these six dimensions elaborating on the combinations of variables that elicited the strongest judgments.

Off-putting: The Durbin test result for this dimension was significant $\left(T_{2}=25.078, p<\right.$ $.0005)$. Subsequent pairwise comparisons showed that the only variant evaluated as off-putting was 'thank you' with non-rising intonation and without a familiar AT in high imposition contexts. $\theta e_{n} \sqrt{C^{h}} \cdot \boldsymbol{u}$ with non-rising intonation and without a familiar AT was so evaluated in relation to both other ' $\theta$ ench $u$ and efiveri'stov variants (Figure 9). 


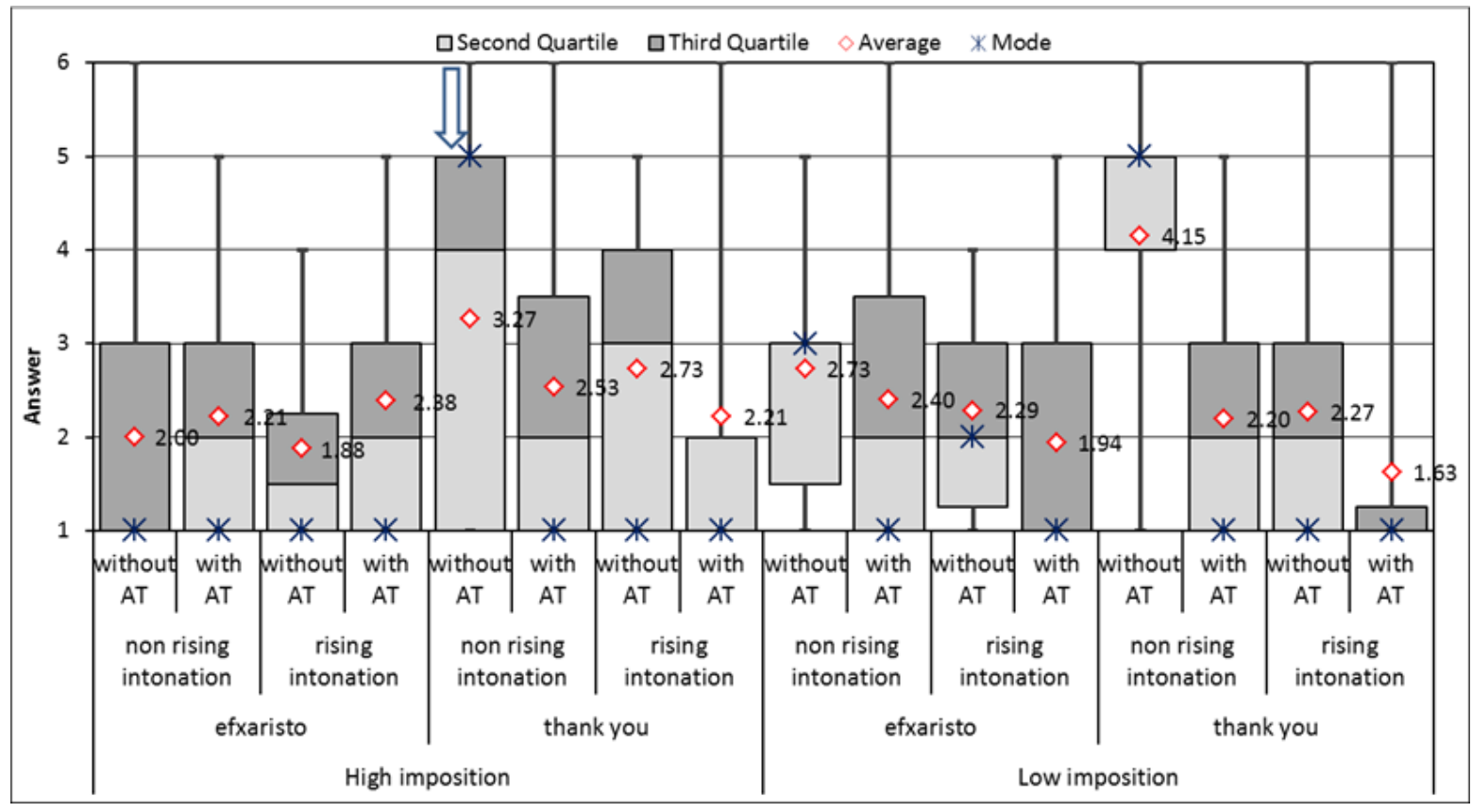

Figure 9: Boxplots, mean and mode values for the 'off-putting' dimension.

Arrogant: The Durbin test result for this dimension was significant $\left(T_{2}=72.692, p<.0005\right)$. Pairwise comparisons showed that efferisto variants were generally evaluated as less arrogant than ' $\theta$ ench $\boldsymbol{u}$ ones and this effect was heightened in high-imposition contexts, in which ' $\theta$ ench: $\boldsymbol{u}$ variants were generally judged as more arrogant (Figure 10). The addition of a familiar AT seems to have a uniform effect here, consistently reducing the arrogance of any variant it is added to. The sole exception to this are ' $\theta \boldsymbol{e n} \boldsymbol{c}^{h}: \boldsymbol{u}$ variants with rising intonation used in high-imposition contexts: adding a familiar AT to these variants is apparently not enough to counteract their arrogance.

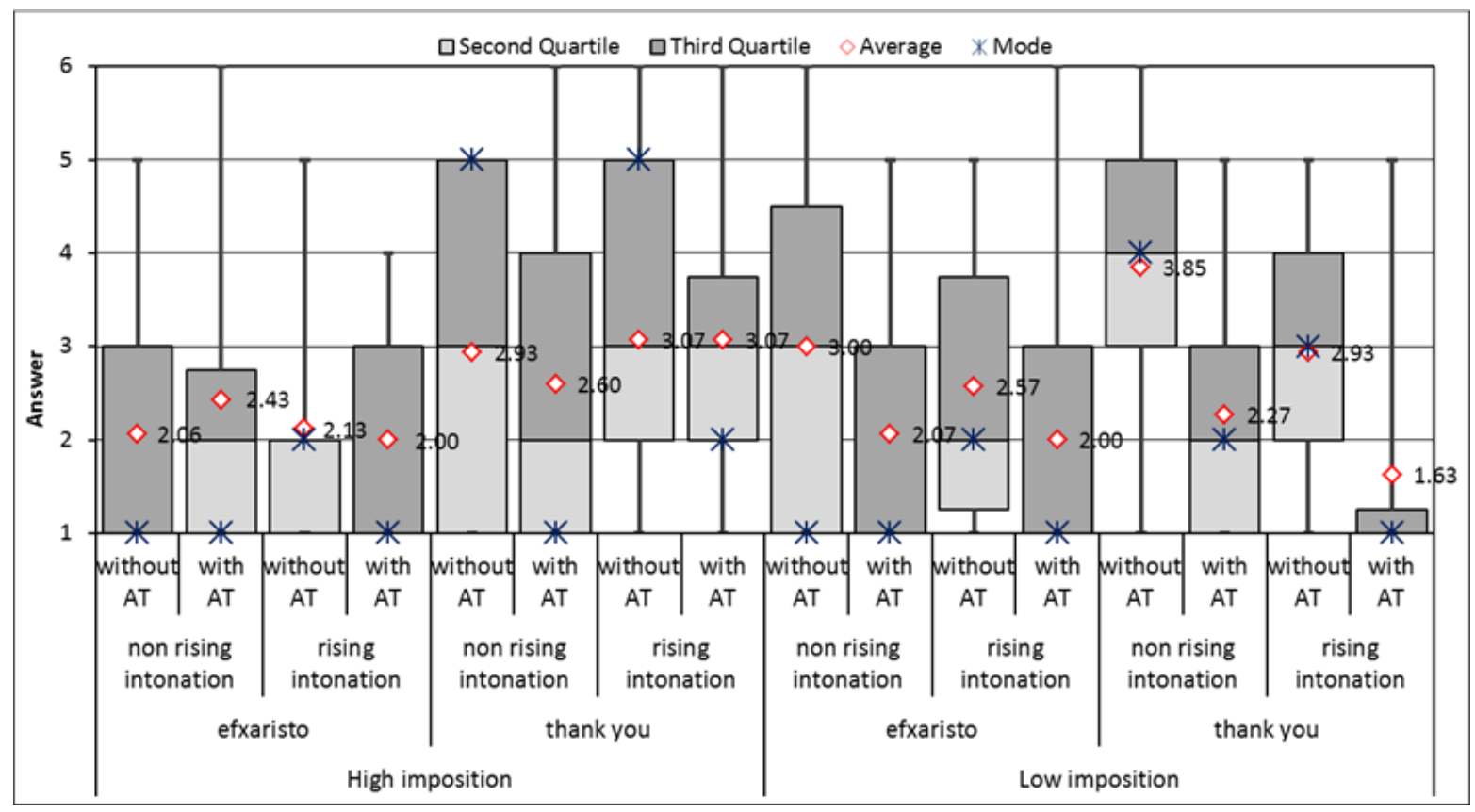

Figure 10: Boxplots, mean and mode values for the 'arrogant' dimension. 
Friendly: Likewise, the addition of a familiar AT generally increases the friendliness of efferi'sto in low-imposition contexts compared to efferi'sto without AT (Figure 11). The addition of the AT also increased friendliness in the case of ' $\theta \boldsymbol{e n c h} \cdot \boldsymbol{u}$ in low-imposition contexts with non-rising intonation. These comparisons were significant $(p<.0005$ in all cases), even though the Durbin test did not yield a significant overall result for this dimension $\left(T_{2}=1.837, p=.101\right)$.

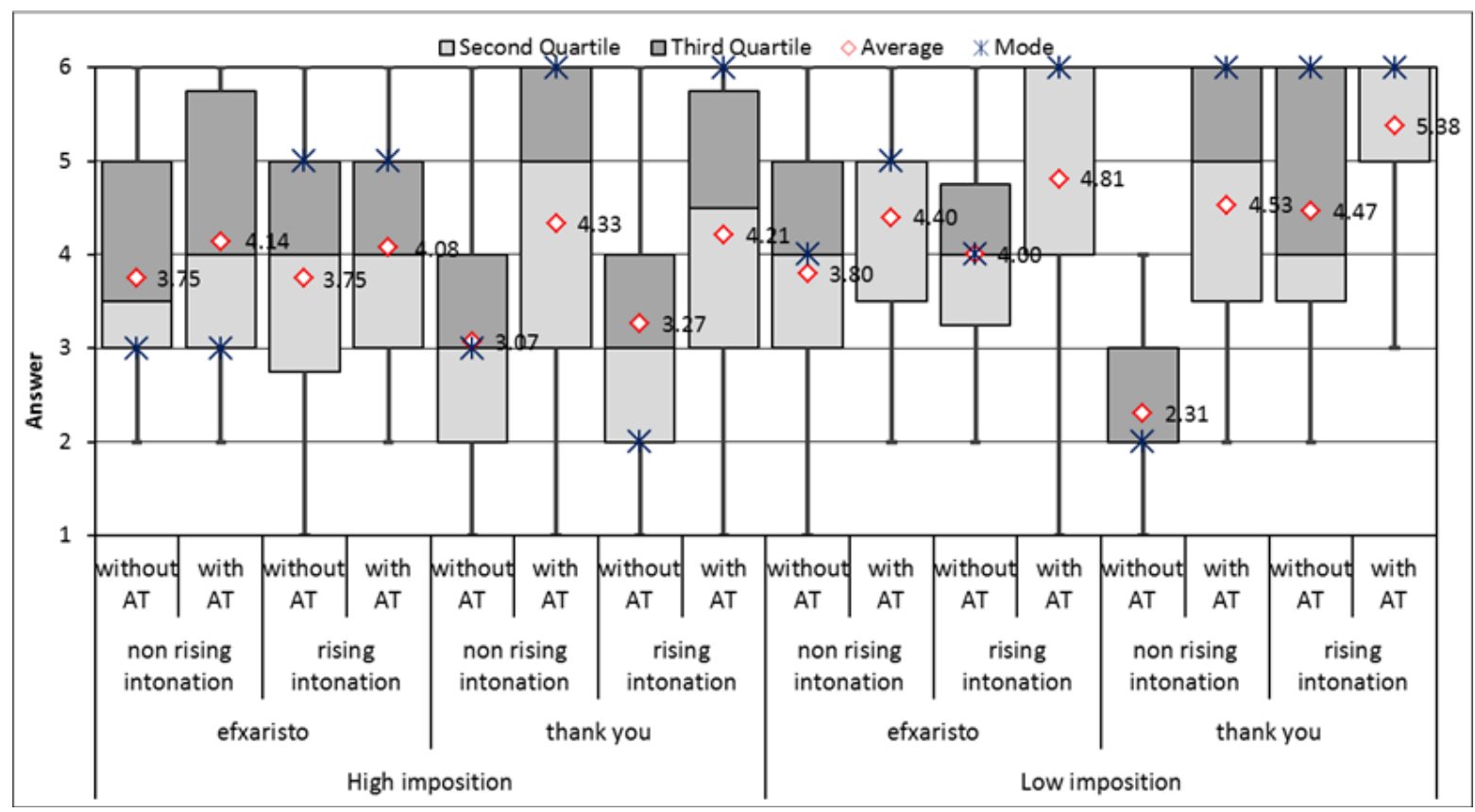

Figure 11: Boxplots, mean and mode values for the 'friendly' dimension.

Formal: The test result for this dimension was significant $\left(T_{2}=38.301, p<.0005\right)$. Pairwise comparisons showed that, overall, efieri'sto variants are evaluated as more formal than ' $\theta e n c^{h}: \boldsymbol{u}$ variants, irrespective of context, and so are, secondarily, variants with non-rising intonation (Figure 12). 


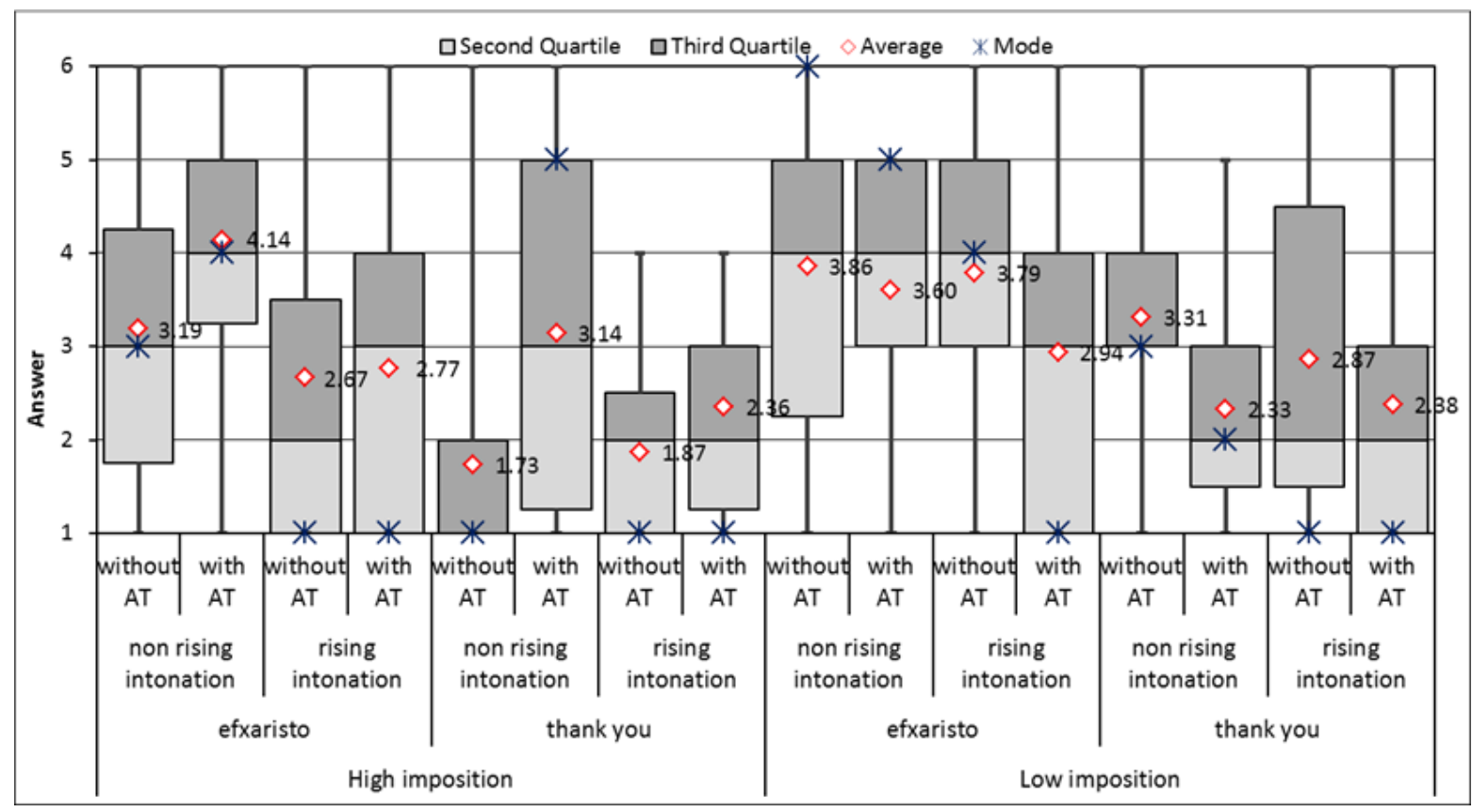

Figure 12: Boxplots, mean and mode values for the 'formal' dimension.

Curt: The test result for this dimension was significant $\left(T_{2}=15.652, p<.0005\right)$. Pairwise comparisons showed that ' $\theta \boldsymbol{e n c} \cdot \boldsymbol{u}$ in high-imposition contexts, uttered with non-rising intonation and without a familiar AT, is judged as curt (Figure 13). No other variant was judged as curt.

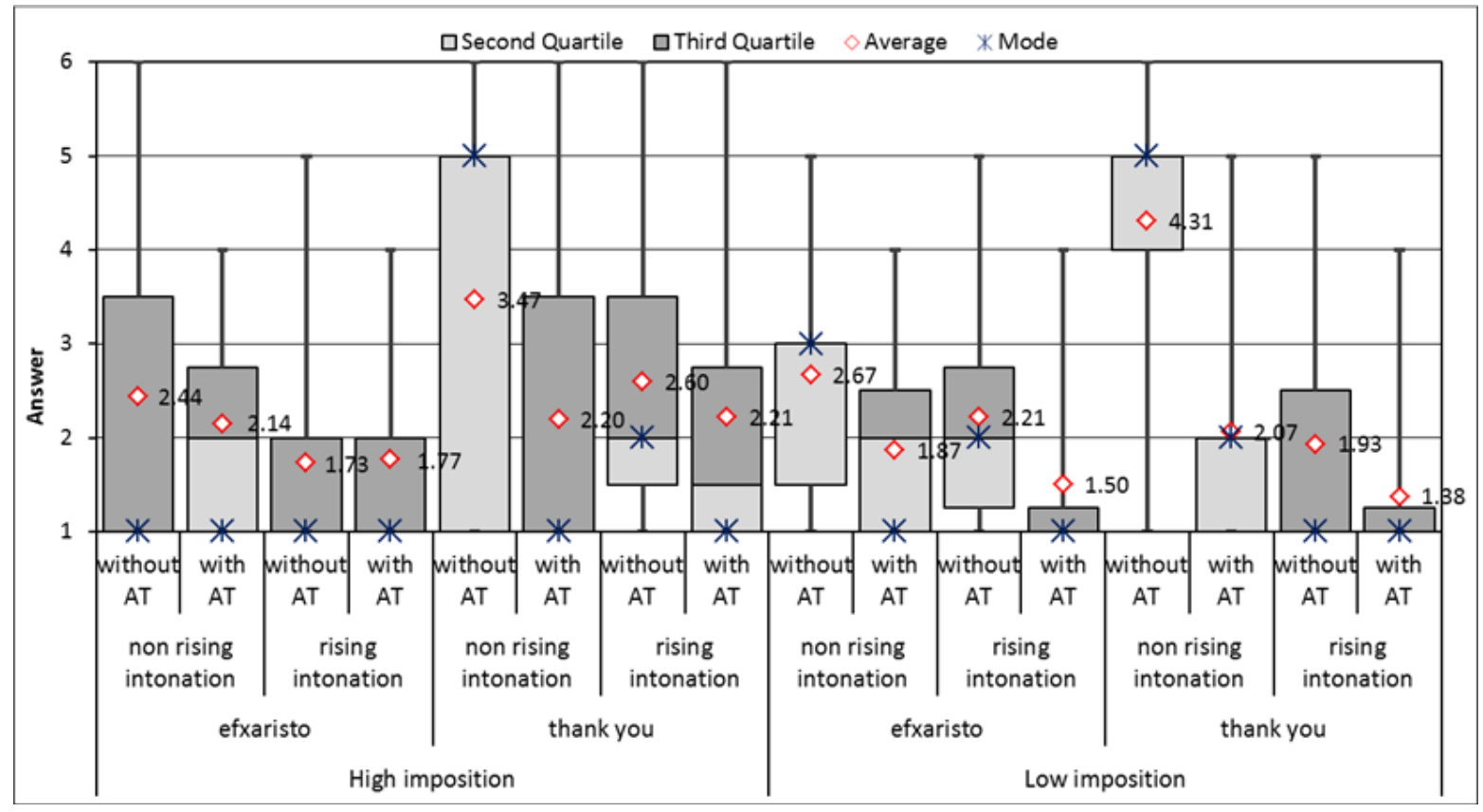

Figure 13: Boxplots, mean and mode values for the 'curt' dimension.

Phony: The test result for this dimension was significant $\left(T_{2}=66.945, p<.0005\right)$. Pairwise comparisons showed that ' $\theta \boldsymbol{e n} \boldsymbol{c}^{h}$ : $\boldsymbol{u}$ variants are generally found to be more phony, especially in high-imposition contexts and when uttered with rising intonation or not accompanied by a familiar AT. They are also found to be phony in low-imposition contexts if they are not 
accompanied by a familiar AT. efferi' sto variants can also be seen as phony, but only in lowimposition contexts (Figure 14).

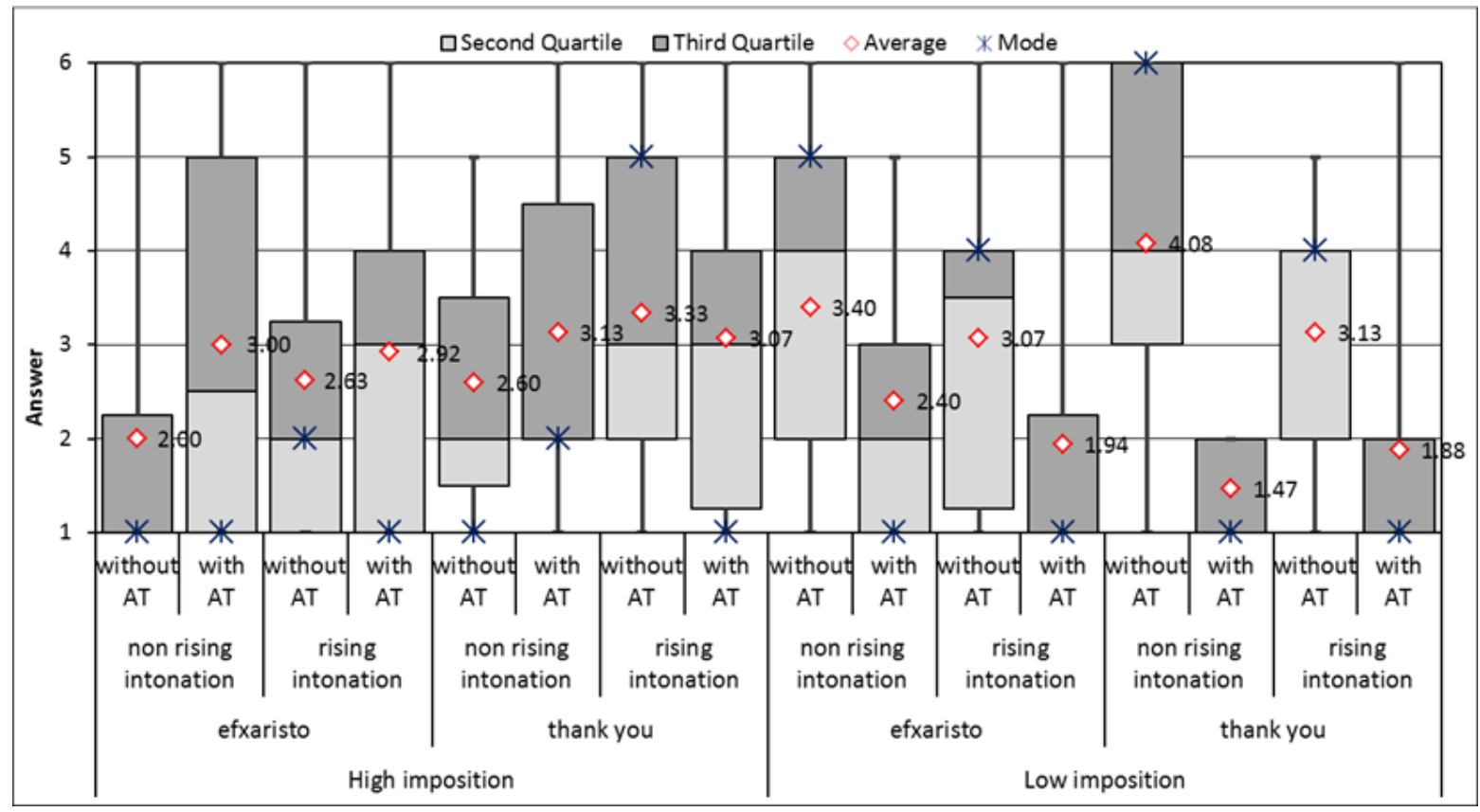

Figure 14: Boxplots, mean and mode values for the 'phony' dimension.

Polite: Although differences between 'polite' and other dimensions were only significant at $\alpha=.05$ (i.e. not at the stricter $\alpha=.001$ adopted for the other dimensions reported above), we briefly consider the dimensions alongside which subjects selected 'polite' in the different contexts investigated, as these can shed some light onto the content of 'polite' for Cypriot Greek speakers (their conceptualizations of politeness1). Of the two thanking items, subjects

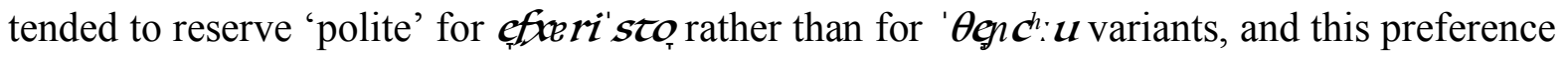
was stronger in low-imposition contexts than in high-imposition ones (Figure 15). Moreover, when they selected 'polite' in these contexts, they frequently also selected 'friendly', 'sincere' and 'formal' to characterize the same variants. 


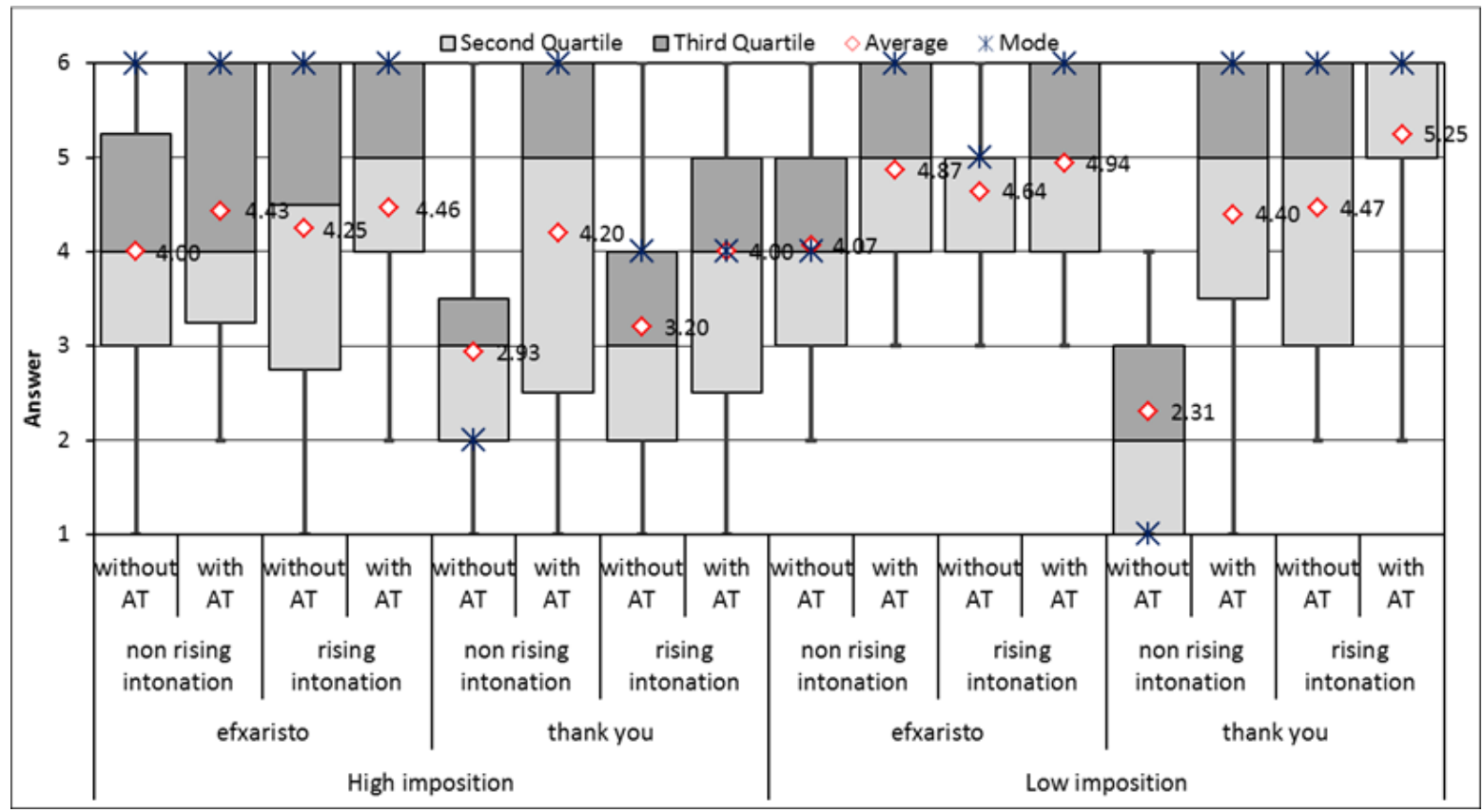

Figure 15: Boxplots, mean and mode values for the 'polite' dimension.

\subsection{Discussion}

Experiment 2 revealed the following general trends: while both 'Aench: $\boldsymbol{u}$ and efueri'sto are generally positively evaluated in low-imposition contexts, in high-imposition ones ' $\theta$ en $\boldsymbol{c}^{h}: \boldsymbol{u}$ can be negatively evaluated, being judged more off-putting, more curt, more arrogant, and more phony. These evaluations can, however, be curbed by the addition of a familiar AT, which has a uniformly positive effect (increasing friendliness and/or decreasing arrogance) on the evaluation of any variant it is added to. Furthermore, the evaluation of ' $\theta e n c^{h}: \boldsymbol{u}$ as offputting and curt in high-imposition contexts is heightened by non-rising intonation, while the converse is true of arrogant and phony (these judgements are heightened by rising intonation in the same contexts). Turning to effieri' stovariants, the only dimension they are significantly associated with is formality. And while efferi'sto variants are generally positively evaluated, they can also be judged as phony in low-imposition contexts, especially when they are uttered with non-rising intonation and without a familiar AT. These findings have several interesting theoretical implications.

The finding that in high-imposition contexts, which require expression of a higher degree of gratitude, ' $\theta e n c^{h} \cdot \boldsymbol{u}$ variants can sound phony and curt, while in low-imposition ones, which require only token acknowledgement, it is efferi'sto that can sound phony, suggests that the two lexical variants encode different degrees of indebtedness in Cypriot Greek. This is in line with Terkourafi's earlier claims (see Figure 1), while also refining them by showing that ' $\theta$ ench $u$ can do some "real thanking after all" (2011: 225). The current experimental results thus afford us with a more nuanced picture of the landscape of thanking items in Cypriot Greek. Specifically, they suggest that ' $\theta$ ench: $\boldsymbol{u}$ can serve as an informal variant of effieri'sto in low-imposition contexts, encoding an appropriately small degree of indebtedness, whereas efferi'sto can come across as phony in those same contexts precisely because the degree of indebtedness it encodes is proportionately much higher. This division of labor between borrowed ' $\theta \boldsymbol{e n c h} \cdot \boldsymbol{u}$ and inherited efxeri'sto is reminiscent of Peterson and Vaattovaara's (2014) claim that, compared with the inherited term 'kiitos', English pliis functions as a 
positive politeness marker in Finnish. It is also in line with Sifianou's (1992: 168) claim that the adverbial 'liyo ('a little') in Standard Modern Greek requests functions as an informal variant of pereke 'lo ('please'). In all of these cases, a functional split appears to exist between two terms, one of which is perceived as committing the speaker more explicitly to the feeling expressed (gratitude or desire) than the other.

An even more nuanced picture emerges once the two additional factors manipulated, intonation and the addition of a familiar AT, are taken into account. While addition of a familiar AT seems to express a consistently positively polite indexicality (in the sense of Silverstein 2003), boosting the friendliness and/or decreasing the arrogance of any variant it is added to, the indexicality of rising intonation is rather more ambivalent. In low-imposition contexts, this is generally positively evaluated but in high-imposition ones rising intonation can be negatively evaluated. Taken jointly with our findings from experiment 1 , where rising intonation emerged as the primary indicator of a DM reading, this suggests that, rather than indexing im/politeness directly, rising intonation indexes the speaker's relatively low commitment to the illocutionary point encoded in the lexical item it is applied to. Its further interpretation as polite (or impolite) depends on how this primary indexicality is evaluated in the context at hand. In low-imposition contexts, where only token acknowledgement is expected, this lighthearted approach can be appropriate and rising intonation can be positively evaluated. However, in high-imposition contexts, which entail a higher degree of indebtedness, this same lighthearted approach can come across as frivolous and self-serving, and rising intonation can be judged arrogant and phony - a sign of affectation rather than politeness. ${ }^{8}$ This is even more so when rising intonation is applied to a lexical item such as ' $\theta$ ench $\boldsymbol{c}^{h} \boldsymbol{u}$ which encodes less indebtedness to begin with. High rates of perceiving ' $\theta \boldsymbol{g} n \boldsymbol{c}^{h}: \boldsymbol{u}$ with non-rising intonation in high-imposition contexts as curt and off-putting can be explained along similar lines: by more or less asserting the speaker's lower indebtedness encoded in ' $\theta$ en $\sqrt{\boldsymbol{c}^{h}}: \boldsymbol{u}$ (rather than expressing a lower degree of commitment to it, as rising intonation would do), these variants are again evaluated negatively in high-imposition contexts, but for different reasons.

It is then possible to say that, while the addition of a familiar AT functions as a politeness marker in its own right (and a positively polite one at that, confirming Brown and Levinson's predictions in this respect, 1987: 107-108), rising intonation does so only in conjunction with the context at hand. In terms of Eckert's (2008) notion of the indexical field, then, rising intonation is only indirectly related (i.e., as a second-order indexical) with im/politeness. At first-order, it is associated with lack of conviction or commitment to one's illocutionary point, which can sound duly lighthearted (hence be positively evaluated) in low-imposition contexts but unduly frivolous (hence be negatively evaluated) in high-imposition ones.

A final point regards the characterizations 'formal' and 'polite', which subjects primarily applied to efixeri'sto variants. efferi'sto variants were generally judged as 'formal' in both low- and high-imposition contexts, while some (those with a familiar AT and, secondarily, with rising intonation) were also singled out as 'polite' in low-imposition ones. Since efferi'sto is the inherited Greek term and given the long history of diglossia in Cyprus, with concomitant hierarchical ranking of the standard (SMG) and local (Cypriot Greek) codes, these findings point to the fact that a central ingredient of 'politeness' (=politeness1) in Cypriot

\footnotetext{
8 'Politeness' here refers to the Cypriot Greek understanding of politeness1, which is further analyzed at the end of this section.
} 
Greek is association with the standard code. This chimes in with informal reports by native speakers that politeness is a matter of "education" and "good upbringing," both of which entail verbal ability in the standard code. While this does not guarantee that the speaker will be perceived as 'friendly' (indeed, the highest friendliness ratings were achieved by 'Oench $u$ variants in low-imposition contexts), it does entail a different kind of positive evaluation (namely, for reasons of prestige). The fact that efxeri'sto is characterized as 'polite' mostly in low-imposition contexts, combined with our earlier claim that it encodes a higher degree of indebtedness, further suggests an understanding of 'politeness' (=politeness1) in Cypriot Greek as what goes above and beyond what is required by the context at hand, in line with Watts' (2003) distinction between "polite" and "politic". However, unlike Watts's claims regarding the ambivalence of 'politeness' in English and whether it constitutes a good, positive attribute, or a bad, negative one (2003: 23-25, 252-255), 'politeness' itself in Cypriot society appears to retain a positive value. Thus, when efferi'stor variants in low-imposition contexts are characterized as 'polite', this is often accompanied by the characterizations 'friendly' and 'sincere', but when they are characterized as 'phony' the term 'polite' no longer applies to them.

Overall, our findings from experiment 2 confirm the more positive evaluation of ' $\theta e n c^{h}: u$ in low- rather than high-imposition contexts. ' $\theta$ enc $\boldsymbol{c}^{h} \boldsymbol{u}$ in these contexts is judged as overall more friendly, with the variant accompanied by rising intonation and a familiar AT eliciting the strongest and most consistent judgements across subjects in this regard. Conversely, efferi'sto is judged relatively more favorably in high- than in low-imposition contexts, where it is perceived as more sincere and, secondarily, more formal. Its positive evaluation in these contexts is, again, heightened by the addition of rising intonation and a familiar AT.

Rising intonation and the addition of a familiar AT thus emerge as additional politeness markers, which interact with the lexically encoded politeness of efferi'sto vs. 'Aench:u. Interestingly, while their impact on subjects' evaluations remains comparable in lowimposition contexts (either of them adds to their positive evaluation and cumulatively they do so the most), they come apart in high-imposition contexts: while the addition of a familiar AT continues to have a positive effect in those contexts, rising intonation can instead be perceived as arrogant and phony. This suggests a context sensitivity in the interpretation of rising intonation which is absent from the use of a familiar AT.

\section{Limitations}

The main limitation of our study was that our samples were too homogeneous. Subjects for both experiments were highly educated (12+ years of education) young adults residing in the capital Lefkosia. While this heightens our confidence in these results as representative of the speech of this particular group, it precludes generalizing our findings to speakers of Cypriot Greek across the board. More representative samples including older speakers, rural populations, and other Greek-speaking areas of the island (Lemessos, Larnaka and Pafos) are needed to reach more robust conclusions about the variety as a whole. At the same time, the fact that more than three quarters of the population are under 54 with a median age of $35.7,{ }^{10}$

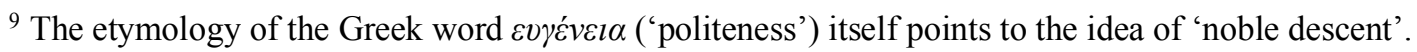

102014 figures; http://www.indexmundi.com/cyprus/demographics_profile.html.
} 
with over two thirds $(67 \%)^{11}$ residing in cities gives us some confidence that our sample is representative of the average Cypriot. Some subjects' reporting during post-experimental debriefing that in their own speech they exclusively or mostly use efxeri'sto (somewhat at odds with the generally positive evaluation of ' $\theta e n c^{h}: u$ in experiment 2) may be related to ideological factors. This would be in line with Terkourafi's (2005b) findings regarding V forms and their opposing interpretations by native speakers with different ideological orientations toward SMG. Given such informal reports, expanding our sample to populations from more diverse backgrounds would allow us to track the possible effects of ideology, class and change in attitudes over time.

\section{Concluding remarks}

We report on two experiments aiming to provide an in-depth picture of the landscape of thanking items in Cypriot Greek. Earlier corpus results (Terkourafi 2011) had suggested a division of labor between inherited efferi'sto and borrowed ' $\theta$ ench: $u$, whereby the former was primarily charged with doing thanking while the latter more frequently performed DM functions. By experimentally controlling for both phonetic (e.g., intonation) and social (gender, degree of imposition) dimensions of variation, we gained a better understanding of the possible meanings of these two terms and their evaluation by native speakers. Terkourafi's earlier claims were confirmed up to a point, while new insights also emerged. Specifically, we found that ' $\theta \boldsymbol{e n} \boldsymbol{c}^{h} \cdot \boldsymbol{u}$ can also take on thanking functions, especially when uttered with nonrising intonation and, secondarily, when produced and/or interpreted by women. Compared with efferi'sto, ' $\theta$ ench: $u$ continues to encode a lower degree of indebtedness and as such emerges as an informal variant of efxeri'sto rather than in competition with it (contrary to fears about the extensive infiltration of English into Greek in Cyprus; see Tsiplakou 2009 for a review). In this role, ' $\theta \boldsymbol{e} n \boldsymbol{c}^{h}: \boldsymbol{u}$ is aided by the addition of a familiar AT and can express further (positive) indexicalities such as 'friendliness'. However, if inappropriately extended to high-imposition contexts, its nonchalance can be negatively evaluated. Intonation turned out to be crucial in this respect. Rising intonation, in particular, turned out to express as its primary indexicality a lower degree of commitment to the illocutionary point expressed, which is positively evaluated in low-imposition contexts but can be negatively evaluated in highimposition ones. Thus, contrary to the addition of a familiar AT which functions as a marker of politeness (i.e. positively evaluated) in and of itself, the role of intonation in politeness evaluations was found to be more variable and mediated by context.

The experimental methodology adopted in this work also has methodological implications. In terms of design, we opted for auditory delivery of the contexts supported by visual prompts (drawings), which we believe can lead to more natural results for non-standard varieties such as Cypriot Greek. More importantly, our analysis showed that while the total $\mathrm{im} /$ politeness import of an expression is the combined effect of different dimensions (lexical, prosodic etc.), experimental manipulation of these dimensions allows us to observe more closely the effect of each of these dimensions on the im/polite evaluation of an utterance as a whole, as well as their interaction and relative weighting in different circumstances. In this way, the experimental methodology presented in this chapter represents a promising path for future analyses of multi-modal aspects of im/politeness.

${ }^{11} 2014$ figures; http://www.tradingeconomics.com/cyprus/urban-population-wb-data.html. 


\section{Acknowledgements}

We thank Elizabeth Peterson, whose invitation to present our work at the $14^{\text {th }}$ International Pragmatics (IPrA) conference (Antwerp, 2015) motivated us to embark on this project, as well as the editors of this volume, who encouraged us to develop it further. All errors remain our own.

\section{References}

Aijmer, K. (1996). Conversational Routines in English: Convention and Creativity. London: Longman.

Archer, D., K. Aijmer, \& Wichmann, A. (2012). Pragmatics: An Advanced Resource Bookfor Students. New York: Routledge.

Armostis, S., K. Christodoulou, M. Katsoyannou, \& Themistocleous, C. (2014). Addressing writing system issues in dialectal lexicography: the case of Cypriot Greek. In C. Dyck, T. Granadillo, K. Rice and J.E. Rosés Labrada, eds, Dialogue on Dialect Standardization. Cambridge: Cambridge Scholars Publishing, pp. 23-38.

Arvaniti, A. (2010). Linguistic practices in Cyprus and the emergence of Cypriot Standard Greek. Mediterranean Language Review 17, 15-45.

Austin, J.L. (1962). How to Do Things with Words. Oxford: Clarendon.

Boersma, P. \& D. Weenink (2016). Praat: doing phonetics by computer [Computer program]. Version 5.4.08. http://www.praat.org/

Brown, P. \& S.C. Levinson (1987). Politeness: Some Universals in Language Usage. Cambridge: Cambridge University Press.

Conover, W. J. (1999). Practical Nonparametric Statistics (Third ed.). New York: Wiley \& Sons.

Eckert, P. (2008). Variation and the indexical field. Journal of Sociolinguistics 12, 453-76.

Forster, K. I., \& J. C. Forster (2003). DMDX: A windows display program with millisecond accuracy. Behavior Research Methods, Instruments, \& Computers 35, 116-124.

Fotiou, K. (2015). An empirical study of English in Cypriot Greek conversations and print media. Unpublished $\mathrm{PhD}$ diss. University of Essex.

Glass, G.V., P.D. Peckham, \& J.R. Sanders (1972). Consequences of failure to meet assumptions underlying fixed effects analyses of variance and covariance. Review of Educational Research 42, 237-288.

Labov, W. (1994). Principles of Linguistic Change. Volume I: Internal Factors. Oxford: Blackwell. 
Makri Tsilipakou, M. (2001). Congratulations and bravo. In Bayraktaroglu, A. \& M. Sifianou (2001) Linguistic Politeness Across Boundaries: The Case of Greek and Turkish. Amsterdam: John Benjamins, 137-176.

Newton, B. (1968). Spontaneous Gemination in Cypriot Greek. Lingua 20, 15-57.

Newton, B. (1972). Cypriot Greek: Its phonology and inflections. The Hague: Mouton.

Pavlidou, T. (1994). Contrasting German-Greek politeness and the consequences. Journal of Pragmatics 21, 487-511.

Pavlidou, T. (2001). Evidence in the classroom? Evidence from a Greek high school. In Bayraktaroglu, A. \& M. Sifianou (2001) Linguistic Politeness Across Boundaries: The Case of Greek and Turkish. Amsterdam: John Benjamins, 105-136.

Peterson, E. \& Vaattovaara, J. (2014). Kiitos and pliis: The relationship of native and borrowed politeness markers in Finnish. Journal of Politeness Research 10 (2), 247-269.

Romaine, S. (2000). Language in Society: An Introduction to Sociolinguistics (Second ed.). Oxford: Oxford University Press.

Salmon, W. \& J. Gómez Menjívar (2014). Whose Kriol is Moa Beta? Prestige and Dialects of Kriol in Belize. Berkeley Linguistics Society 40, 457-479.

Sifianou, M. (1992a). Politeness Phenomena in England and Greece: A Cross-Cultural Perspective. Oxford: Clarendon.

Sifianou, M. (1992b). The use of diminutives in expressing politeness. Journal of Pragmatics $17,155-173$.

Sifianou, M. (1995). Do we need to be silent to be extremely polite? Silence and FTAs. International Journal of Applied Linguistics 15(1): 95-110.

Sifianou, M. (2001). "Oh! How appropriate": Compliments and politeness. In A. Bayraktaroğlu and M. Sifianou (eds), Linguistic Politeness across Boundaries: The Case of Greek and Turkish. Amsterdam: John Benjamins, 391-430.

Sifianou, M. (2015). "The concept of politeness in Greek." Invited talk at the 12th International Conference of Greek Linguistics, Freie Univeristät Berlin, 16-19 September 2015.

Silverstein, M. (2003). Indexical order and the dialectics of sociolinguistic life. Language \& Communication 23 (3-4), 193-229.

Studebaker, G. A. (1985). A "Rationalized" Arcsine Transform. Journal of Speech and Hearing Research 28, 455-462.

Terkourafi, M. (1999). Frames for politeness: A case study. Pragmatics 9(1), 97-117. 
Terkourafi, M. (2005a). Understanding the present through the past: Processes of koineisation on Cyprus. Diachronica 22(2), 309-372.

Terkourafi, M. (2005b). Identity and semantic change: Aspects of T/V usage in Cyprus. Journal of Historical Pragmatics 6(2), 283-306.

Terkourafi, M. (2005c). An argument for a frame-based approach to politeness: Evidence from the use of the imperative in Cypriot Greek. In Lakoff, R. \& S. Ide (eds.) Broadening the Horizon of Linguistic Politeness. Amsterdam: John Benjamins, 99-116.

Terkourafi, M. (2007). Perceptions of difference in the Greek sphere: The case of Cyprus. Journal of Greek Linguistics 8, 60-96.

Terkourafi, M. (2009). Finding face between Gemeinschaft and Gesellschaft: Greek perceptions of the in-group. In Haugh, M. \& F. Bargiela-Chiappini (eds.) Face, Communication, and Social Interaction. London: Equinox, 269-288.

Terkourafi, M. (2011). Thank you, Sorry, and Please in Cypriot Greek: What happens to politeness markers when they are borrowed across languages? Journal of Pragmatics 43, $218-235$.

Tsiplakou, S. (2006). Cyprus: language situation. Encyclopedia of Language and Linguistics, 337-339.

Tsiplakou, S. (2009). English in Cyprus: Outer or expanding circle. Anglistik-International Journal of English Studies 20(2), 75-88.

Tsiplakou, S., A. Papapavlou, P. Pavlou \& M. Katsoyannou (2006). Levelling, koineization and their implications for bidialectism. Hinskens, F. (ed.) Language Variation. European Perspectives. Selected Papers from the 3rd International Conference on Language Variation in Europe (ICLaVE 3), University of Amsterdam, 23-25 June 2005. Amsterdam: John Benjamins, 265-276.

Tzanne, A. (2001). 'What you're saying sounds very nice and I'm delighted to hear it': some considerations on the functions of presenter-initiated simultaneous speech in Greek panel discussions. In Bayraktaroğlu, A. \& M. Sifianou (eds.) Linguistic Politeness across Boundaries: The Case of Greek and Turkish. Amsterdam: John Benjamins, 271-306.

Watts, R. J. (2003). Politeness. Cambridge: Cambridge University Press.

Wells, J. C. (2006). English Intonation: an Introduction. Cambridge: Cambridge University Press.

Woolard, K. (1989). Double Talk: Bilingualism and the Politics of Ethnicity in Catalonia. Stanford: Stanford University Press.

Wouters, C. (2007). Informalization: Manners and Emotions Since 1890. Los Angeles: Sage. 


\section{Appendix A}

Original Greek term English translation

1.

$$
\text { '́ } \xi 0 \pi v o \zeta / \eta \quad \text { intelligent }
$$

2.

$\alpha \dot{\alpha} \varepsilon \sigma \tau \sigma \varsigma / \eta \quad$ unrefined

3.

4.

5.

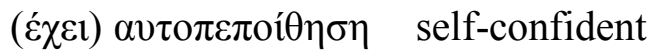

6.

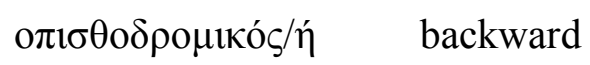

7.

8

10.

11.

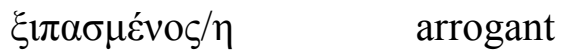

$\varphi \imath \lambda \iota \kappa o ́ \varsigma / \eta ́ r$ friendly

12.

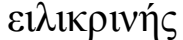
sincere

$\alpha \pi$ ó $\mu \alpha \kappa \rho \circ \varsigma \eta$ distant

$\varepsilon \pi i ́ \sigma \eta \mu \sigma / \eta$ formal

$\alpha \pi$ ó $\operatorname{lo\mu o\varsigma } / \eta \quad$ curt

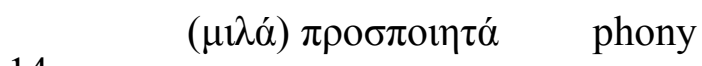

